OPEN ACCESS

Edited by:

Gabriel Gutiérrez-Ospina, National Autonomous University of

Mexico, Mexico

Reviewed by:

Francesco Di Meo,

Università di Napoli "Federico II", Italy

Pedro Gomes,

University of Coimbra, Portugal

${ }^{*}$ Correspondence: Shanthi Srinivasan

ssrini2@emory.edu

Specialty section: This article was submitted to

Neurodegeneration,

a section of the journal

Frontiers in Neuroscience

Received: 05 October 2020 Accepted: 02 December 2020 Published: 22 December 2020

Citation: Chandramowlishwaran P, Vijay A, Abraham D, Li G, Mwangi SM and Srinivasan S (2020) Role of Sirtuins in Modulating Neurodegeneration of the Enteric Nervous System and Central

Nervous System

Front. Neurosci. 14:614331.

doi: 10.3389/fnins.2020.614331

\section{Role of Sirtuins in Modulating Neurodegeneration of the Enteric Nervous System and Central Nervous System}

\author{
Pavithra Chandramowlishwaran ${ }^{1,2}$, Anitha Vijay ${ }^{3}$, Daniel Abraham ${ }^{4}, \mathrm{Ge} \mathrm{Li}^{1,2}$, \\ Simon Musyoka Mwangi ${ }^{1,2}$ and Shanthi Srinivasan ${ }^{1,2 *}$ \\ ${ }^{1}$ Division of Digestive Diseases, Department of Medicine, Emory University School of Medicine, Atlanta, GA, United States, \\ ${ }^{2}$ Research-Gastroenterology, Atlanta Veterans Affairs Health Care System, Decatur, GA, United States, ${ }^{3}$ Department of \\ Veterinary and Biomedical Sciences, The Pennsylvania State University, University Park, PA, United States, ${ }^{4}$ Sidney Kimmel \\ Medical College, Thomas Jefferson University, Philadelphia, PA, United States
}

Neurodegeneration of the central and enteric nervous systems is a common feature of aging and aging-related diseases, and is accelerated in individuals with metabolic dysfunction including obesity and diabetes. The molecular mechanisms of neurodegeneration in both the CNS and ENS are overlapping. Sirtuins are an important family of histone deacetylases that are important for genome stability, cellular response to stress, and nutrient and hormone sensing. They are activated by calorie restriction (CR) and by the coenzyme, nicotinamide adenine dinucleotide $\left(\mathrm{NAD}^{+}\right)$. Sirtuins, specifically the nuclear SIRT1 and mitochondrial SIRT3, have been shown to have predominantly neuroprotective roles in the CNS while the cytoplasmic sirtuin, SIRT2 is largely associated with neurodegeneration. A systematic study of sirtuins in the ENS and their effect on enteric neuronal growth and survival has not been conducted. Recent studies, however, also link sirtuins with important hormones such as leptin, ghrelin, melatonin, and serotonin which influence many important processes including satiety, mood, circadian rhythm, and gut homeostasis. In this review, we address emerging roles of sirtuins in modulating the metabolic challenges from aging, obesity, and diabetes that lead to neurodegeneration in the ENS and CNS. We also highlight a novel role for sirtuins along the microbiota-gut-brain axis in modulating neurodegeneration.

Keywords: central nervous system, enteric nervous system, gut microbiota, myenteric plexus, neuronal survival, neurodegeneration, sirtuin (SIRT)

\section{THE EFFECTS OF AGE, OBESITY, AND DIABETES ON NEURODEGENERATION IN THE CNS AND ENS}

Neurodegeneration in the CNS is characterized by a progressive loss of distinct groups of neurons in specific regions of the brain, deposition of misfolded proteins in neurons, and alterations in astrocytes (Przedborski et al., 2003; Maragakis and Rothstein, 2006) which results in cognitive dysfunction, loss of synapses, impaired synaptic plasticity, disrupted neuronal signaling, and cell 
death. The factors that contribute to neuronal stresses in the CNS are aging, neurodegenerative diseases (NDs), comorbidities such as obesity and diabetes, over nutrition via high calorie intake, a lack of physical activity, and genetic background (Popa-Wagner et al., 2020). These stresses and changing physiological demands from oxidative damage, protein aggregation, dietary changes, inflammation, high metabolic demands, are counteracted by cells to maintain cellular, protein, and metabolic homeostasis (Squier, 2001; Uttara et al., 2009). Similar to the CNS, the neurons of the enteric nervous system (ENS) or the "brain within the gut," are also prone to neurodegeneration. The ENS is a subdivision of the peripheral nervous system and functions independently of the central nervous system (Nezami and Srinivasan, 2010). The ENS is embedded within the walls of the intestine and directly controls gastrointestinal functions. The neurons and glia in the ENS are structurally organized into two interconnected layers, the myenteric and the submucosal plexi. The myenteric plexus, which is located between the circular and longitudinal muscle layers, regulates gastrointestinal motility whereas the submucosal plexus, which is located between the circular muscle and mucosa, regulates secretory activity. In these plexuses, the neuronal cells form groups of interconnected ganglions that are surrounded by glia. The individual ganglia are connected to each other and to the epithelium by neuronal projections (Nezami and Srinivasan, 2010). The ENS, intestinal epithelium, gut microbiota, and immune cells work in harmony together to ensure the proper functioning of the intestine (Walsh and Zemper, 2019). ENS-related neurodegeneration is particularly evident in individuals with aging and neurodegenerative disorders. Moreover, individuals with aging or NDs also experience symptoms related to gastrointestinal dysmotility especially chronic constipation due to loss of enteric neurons in the myenteric plexus leading to ENS dysfunction (Poirier et al., 2016; Rao and Gershon, 2016). Additional stresses from dietary changes and antibiotic treatments can alter the gut microbiota and also influence ENS function (Carabotti et al., 2015). Further understanding of the factors leading to neurodegeneration of the CNS and ENS is critical and can lead to new therapeutic targets.

\section{Aging Associated Neurodegeneration}

Aging is a multifactorial process accompanied by many changes at the cellular, tissue, and organismal level over time and has shown to be a major risk factor for neurodegeneration of the CNS and the ENS (Wade and Cowen, 2004; Hou et al., 2019). Crosssectional, longitudinal, and quantitative magnetic resonance imaging (MRI) and voxel-based morphometry (VMI) analyses report reduced brain volume and brain atrophy especially in the hippocampus and the prefrontal cortex, in conjunction with a decline in cognitive functioning in older adults (Liu et al., 2003; Terribilli et al., 2011; Ramanoel et al., 2018). In vitro studies in rat

Abbreviations: Ab, Antibody; CR, Calorie restriction; CNS, Central nervous system; ENS, Enteric nervous system; GI, Gastrointestinal; HFD, High-fat diet; KO, Knock out; NDs, Neurodegenerative diseases; NF-кB, Nuclear factor kappa B; PGC-1 $\alpha$, Peroxisome proliferator-activated receptor gamma coactivator 1-alpha; ROS, Reactive oxygen species; Sirtuins, Silent information regulator genes: sirtuins; SCFA, Short chain fatty acid: SCFA; T2D, Type II diabetes; WT, Wild type. primary cortical and hippocampal neurons, cultured long term, demonstrate irreparable DNA damage that underlies normal aging leading to proteostasis and cell senescence (Ishikawa and Ishikawa, 2020). This causes a loss of ability to repair tissues, chemokine and cytokine release, low grade inflammation, and results in age-related neurodegeneration. Population-based studies of cognitively unimpaired aged people reported an accumulation of abnormal protein deposits that positively correlated with age (Elobeid et al., 2016). While age-associated neurodegeneration is accompanied by a gradual loss of neurons, rapid progression in behavioral and cognitive changes have been attributed to chronic neurodegenerative diseases (ND) such as Alzheimer's disease (AD) and Parkinson's disease (PD) (Wilson et al., 2010). Along with these functional declines, the cerebral levels of neurotransmitters such as dopamine, acetylcholine, serotonin, and norepinephrine, and neurotrophic factors such as brain-derived neurotrophic factor (BDNF) and nerve growth factor (NGF) are dramatically reduced in aging brains (Vecchio et al., 2018).

The impact of aging on the ENS is controversial. Enteric neurons from the colon of human tissues have been shown to decrease in the 4 th year of age in both the plexuses with a further loss of $37 \%$ of total neuron population between the ages 20-65 (Gomes et al., 1997). Some studies have reported a loss of $50-60 \%$ of myenteric neurons has been reported in the aging guts and especially the colon of aging rats (Santer and Baker, 1988; Nezami and Srinivasan, 2010) while other studies contrasted that myenteric neuron numbers in the aging colon remain the same albeit with functional changes (Gamage et al., 2013). Neurotransmitters produced by myenteric neurons and neuronal reflexes mediate late neurogenesis and regulate intestinal motility (Cooke, 2000; Nezami and Srinivasan, 2010). Neurons that produce the choline acetyl transferase (ChAT) and neuronal NOS (nNOS) regulate intestinal motility by stimulating and inhibiting intestinal smooth muscles, respectively (Porter et al., 2002). An imbalance in the equilibrium between the nNOSand ChAT-producing neurons can alter the ENS architecture and result in an altered bowel motility (Nezami and Srinivasan, 2010). These changes presumably alter the normally well-orchestrated crosstalk between the enteric neurons and glia. Some studies also report a loss of choline acetyltransferase (ChAT) and no changes in neuronal nitric oxide synthase (nNOS)- expressing myenteric neurons (Phillips et al., 2003; Nezami and Srinivasan, 2010) while other studies report the loss of nNOS and ChAT neurons in the myenteric plexus of aging mice (Becker et al., 2018; Sun et al., 2018). In rats, studies have reported a loss of submucosal neurons in the proximal and distal colon in 12 months old animals when compared to 3 month old animals with a greater loss occurring in the distal colon and maximum loss occurring at 24 months of age (Saffrey, 2013). In samples from human colon and ileum, the myenteric ganglia had a wider area overall, with a larger proportion of them with increased gaps within the ganglia and this correlated with increasing age, that might contribute to gut dysmotility seen in older individuals (Hanani et al., 2004). Factors and pathways cumulatively associated with neurodegeneration in the CNS and the ENS with aging (Wyss-Coray, 2016) are diagrammatically represented in Figure $\mathbf{1}$. 
Metabolic dysfunction

(aging, obesity, diabetes) Central nervous system

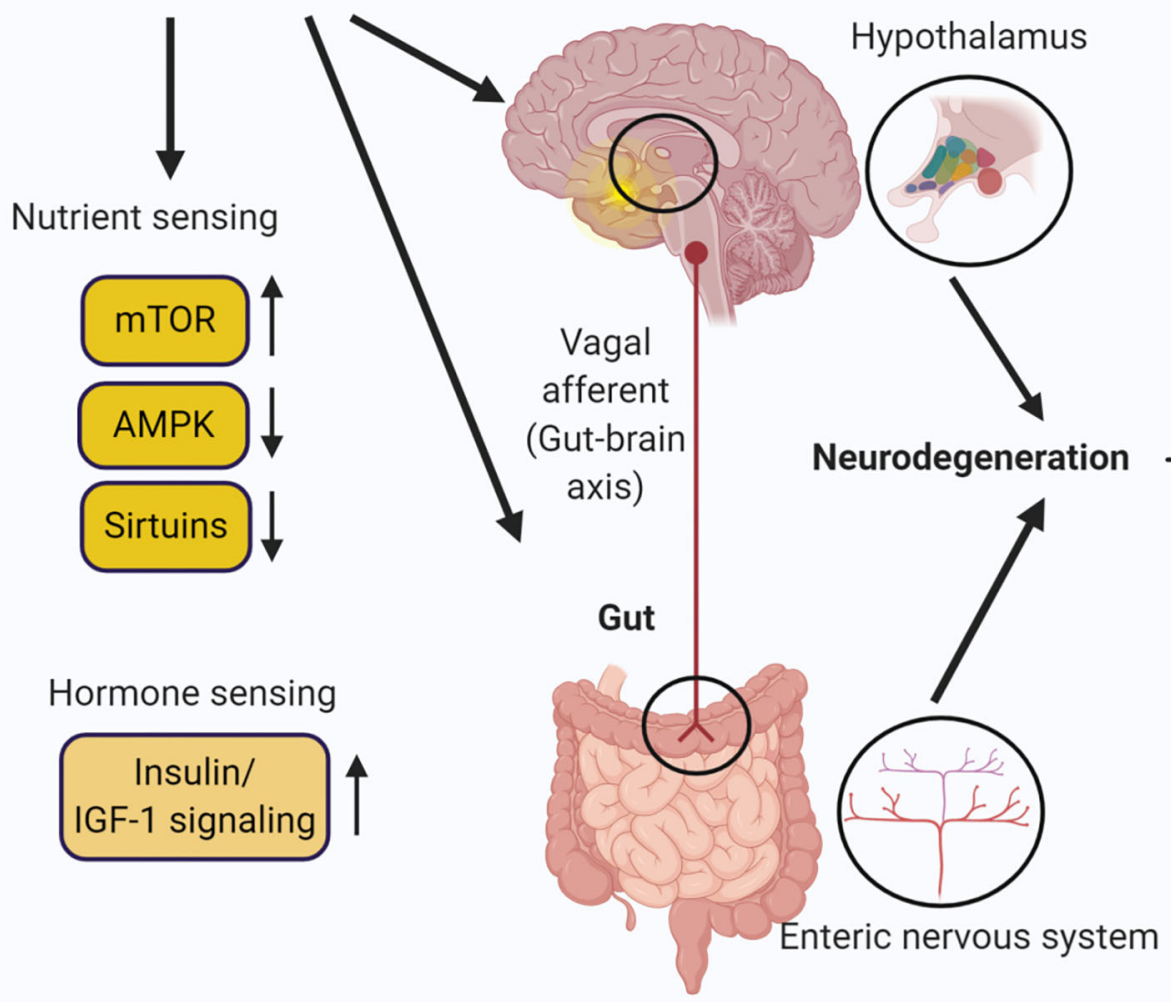

Inadequate nutrient

and hormone sensing

DNA damage

Oxidative damage

Protein misfolding and aggregation

Mitochondrial

dysfunction

Proteostasis defects

Apoptosis

Cellular senescence

Epigenetic changes

FIGURE 1 | Metabolic dysfunction in the central nervous system (CNS) and the enteric nervous system (ENS). Aging, obesity, and diabetes leads to different molecular and physiological changes that cause neurodegeneration in the hypothalamus of the CNS and the ENS of the gut. Created with BioRender.com.

\section{Neurodegeneration Associated With Metabolic Disorders-Obesity and Diabetes}

Obesity and type II diabetes (T2D) have been suggested to accelerate the physiological process of aging (Thorpe and Ferraro, 2004; Kalyani et al., 2017) and obesity is a known risk factor for T2D development (Al-Goblan et al., 2014). In age-dependent and age-independent studies, obesity has been shown to double the risk for mild cognitive impairment, dementia, and AD (Qiu et al., 2009; Hildreth et al., 2012). T2D causes brain atrophy, reduced cerebral glucose metabolism, and insulin resistance in the CNS, and this is also seen in AD (Arnold et al., 2018). Accumulation of misfolded phosphorylated tau and amyloid beta (Arnold et al., 2018) in the brain as well as the islet amyloid polypeptide (amylin) (Raimundo et al., 2020) co-secreted with insulin in the islet beta cells are major pathological features observed in T2D patients who develop AD. As seen in aging, computed tomography demonstrated structural changes in the obese brain such as atrophy in the hippocampus and decreased hippocampal volume (O'Brien et al., 2017). The prefrontal cortex and the hippocampus which are crucial for learning and memory are most vulnerable to obesity-related changes (Bischof and Park, 2015). The hypothalamus controls metabolic homeostasis by sensing nutrients and hormones via autonomic and neuroendocrine signaling to integrate the signals of satiety. Inflammation of the hypothalamus from high fat feeding induces Inhibitor Of Nuclear Factor Kappa-B (IKK $\beta$ )/NF-kB-dependent inflammation, changes satiety control, and increases the risk for developing obesity (Timper and Bruning, 2017). Magnetic resonance imaging (MRI) has shown an inverse relationship between Body Mass Index (BMI) as well as diabetes and brain volume, neuron viability, and gliosis in the hypothalamus (Thomas et al., 2019). Obese individuals with higher BMI with no cognitive defects also displayed decreased gray matter, brain atrophy in the frontal lobe, hippocampus and thalamus when compared to non-obese, thus demonstrating extensive neurodegeneration (Stillman et al., 2017). Vascular defects from obesity leading to cognitive decline include lipotoxicity, diabetes 
impaired insulin metabolism and signaling pathway or defect in glucose transport mechanisms in the brain (Uranga and Keller, 2019). Adipose tissues including white adipose tissue (WAT) are important for metabolism and hormones derived from WAT such as leptin and adiponectin are involved in regulating obesity and diabetes (Stern et al., 2016). Leptin plays a major role in body weight regulation and reducing appetite (Ramos-Lobo and Donato, 2017). Leptin bound to its receptor Ob-Rb has been shown in the cortex and the hippocampus which are major sites of neurodegeneration in aging, $\mathrm{AD}$ and $\mathrm{PD}$ (McGregor and Harvey, 2018). Another adipokine, adiponectin has been shown to have an opposite effect to leptin in inflammation and insulin resistance, and the ratio of leptin to adiponectin is considered as a marker for developing T2D and obesity (FornyGermano et al., 2018). High levels of circulating leptin caused by obesity has been shown to lead to leptin resistance in the hypothalamus and is linked to altered metabolism, inflammation, and neurodegeneration in the brain (Forny-Germano et al., 2018). Obesity and T2D also cause gastrointestinal dysmotility and lead to enteric neuronal degeneration (Yarandi and Srinivasan, 2014). Diabetic autonomic neuropathy has been shown to gastrointestinal disturbances including impaired esophageal transit, gastroparesis, and disorganized intestinal motility with constipation and diarrhea (Verrotti et al., 2014). Our studies in obese and overweight human subjects and in mice fed a high fat diet have demonstrated increased pyroptosis in nitrergic neurons, delayed colonic transit, and impaired electric field stimulation-induced colonic relaxation responses (Ye et al., 2020). In mouse Other studies in the ENS using mice models of high fat diet and obesity induced diabetic neuropathy reported a reduction in hormones such as ghrelin, cholecystokinin (CCK), and leptin levels; and inhibitory neurons expressing nitric oxide synthase (nNOS), vasoactive intestinal peptide (VIP), neuropeptide Y (NPY), and galanin as well as their expression levels (Chandrasekharan and Srinivasan, 2007; Li et al., 2011; Voukali et al., 2011; Stenkamp-Strahm et al., 2015). The neuronal changes characterized by the loss of important neurotransmitters and hormones resulted in altered gastric emptying, diarrhea and constipation that is characteristic of enteric neurodegeneration (Stenkamp-Strahm et al., 2015). Moreover, these alterations could be a compensatory mechanism to increase satiety and decrease food intake to balance weight gain in diet induced obese mice (Coll et al., 2007). A major orchestrator of pathways in response to stresses caused by age- and metabolism-associated neurodegeneration are the sirtuins (Duan, 2013). Factors and pathways cumulatively associated with neurodegeneration in the CNS and the ENS with metabolic dysfunction are summarized in Figure 1.

\section{FUNCTION AND DISTRIBUTION OF SIRTUINS}

\section{Localization, Activators, and Substrates of Sirtuins}

Silent information regulator (Sirtuins) are a family of class III histone deacetylases with a conserved catalytic domain core
TABLE 1 | Overview of sirtuin localization, activity, substrates, functions, and activators.

\begin{tabular}{|c|c|}
\hline Sirtuin & Specific examples relevant to metabolism \\
\hline Localization & $\begin{array}{l}\text { Sirtuins are present in all subcellular compartments and differ in } \\
\text { their substrate specificities (Houtkooper et al., 2012). SIRT1, } \\
\text { SIRT6, and SIRT7 are predominantly nuclear but also detected at } \\
\text { lower levels in cytosol, membrane, and the cytoskeleton. SIRT2 } \\
\text { resides in the cytoplasm (Houtkooper et al., 2012) though it is also } \\
\text { found in the nucleus and the cell membrane (North and Verdin, } \\
\text { 2007). SIRT3, SIRT4, and SIRT5 predominantly localize to the } \\
\text { mitochondria although they are also found in the nucleus and the } \\
\text { cytoplasm (Houtkooper et al., 2012). }\end{array}$ \\
\hline $\begin{array}{l}\text { Enzymatic } \\
\text { activity }\end{array}$ & $\begin{array}{l}\text { SIRT1, SIRT2, SIRT3, SIRT5, and SIRT7 predominantly } \\
\text { deacetylate histone and non-histone proteins; SIRT4 and SIRT6 } \\
\text { act as mono-ADP-ribosyl transferases (Canto et al., 2013). }\end{array}$ \\
\hline Functions & $\begin{array}{l}\text { SIRT1 and SIRT3-Neuronal protection and cell survival, DNA } \\
\text { repair, chromatin remodeling, neuronal differentiation, apoptosis, } \\
\text { energy and metabolic homeostasis, mitochondrial biogenesis, } \\
\text { autophagy, glucose production and insulin secretion, lipid } \\
\text { homeostasis, anti-inflammation (Yamamoto et al., 2007; Duan, } \\
\text { 2013; Giblin et al., 2014). SIRT2 - cell cycle regulation, modulation } \\
\text { of microtubule deacetylation and myelination, tumorigenesis, } \\
\text { neurodegeneration (Yamamoto et al., 2007; Gomes et al., 2015). } \\
\text { SIRT4-insulin secretion, cell cycle regulation (Yamamoto et al., } \\
\text { 2007). SIRT5-Mitochondrial metabolism, urea cycle (Yamamoto } \\
\text { et al., 2007). SIRT6-glucose homeostasis, genome stability, DNA } \\
\text { repair, anti-inflammation (Yamamoto et al., 2007; Zhong and } \\
\text { Mostoslavsky, 2010). SIRT7-rDNA transcription (Wu et al., 2018). }\end{array}$ \\
\hline $\begin{array}{l}\text { Histone } \\
\text { targets }\end{array}$ & $\begin{array}{l}\text { H1, H3, H4 (H1K26, H1K9, H3K9, H3K56, H3K14, H4K16) by } \\
\text { SIRT1; H4K16 by SIRT2; H3, H4 (H3K9, H4K16) by SIRT3; H2B, } \\
\text { H3 (H2BK12, H3K9, H3K56) by SIRT6; and H2A, H2B, H3 } \\
\text { (H3K18) by SIRT7 (Jing and Lin, 2015). }\end{array}$ \\
\hline
\end{tabular}

Non-histone Transcriptional regulators (Martinez-Redondo and Vaquero, 2013; targets Jing and Lin, 2015) related to:

- Stress - p53, Nuclear Factor kappa B (NF-кB), Forkhead Box (FoxO), Superoxide dismutase 2 (SOD2), Poly (ADP-ribose) polymerase (PARP), target of rapamycin (TOR) kinase (TORC2), bcl-2-like protein 4 (Bax), leucine zippers - c-Fos and c-Jun, Uncoupling Protein 2 (UCP2), Heat shock factor 1 (HSF1), bcatenin, E2F Transcription Factor 1 (E2F1), Period Circadian Regulator 2 (PER2), Circadian Locomotor Output Cycles Kaput (CLOCK)

- Metabolism - Peroxisome proliferator-activated receptor gamma coactivator 1-alpha (PGC-1 $\alpha$ ), Liver $X$ receptor $(L X R)$, Farnesoid $X$ receptor (FXR)

- DNA repair - Ku70, Peroxisome proliferator-activated receptor gamma (PPAR $\gamma$ )

- Structural protein - $\alpha$-tubulin

- Chromatin remodeling - p300, MOF

Agonists or Resveratrol [activated SIRT1 and reduced signs of aging without stimulators changing the expression patterns of other sirtuins (Borra et al., 2005)], SRT1720 (Huynh et al., 2013) and oxazolo[4,5-b] pyridines (Bemis et al., 2009) [activated SIRT1 to treat diabetes and insulin resistance in mice (Bemis et al., 2009)], pyrrolo[3,2-b]quinoxalines [promoted SIRT1, SIRT2, and SIRT3-dependent anti-inflammatory properties in vitro (Villalba and Alcain, 2012)], and honokiol [activated SIRT3 and counteracted oxidative stress and mitochondrial damage in $\mathrm{AD}$ and diabetes studies (Ramesh et al., 2018; Zheng et al., 2018)].

of 275 amino acids (Houtkooper et al., 2012). The subcellular localization, enzymatic activities, transcriptional substrates, functions, and activators of sirtuins are briefly explained in Table 1. As cooperative sensors and regulators of nutrients and 
energy metabolism in response to changes in diet and stress, they require $\mathrm{NAD}^{+}$for their enzymatic activity (Anderson et al., 2017). Energy deficits by calorie restriction or cellular stressors increase $\mathrm{NAD}^{+}$levels and activate sirtuins (Guarente, 2013).

\section{Distribution of Sirtuins in the CNS and the ENS}

All of the seven sirtuins are ubiquitously expressed in all human tissues (Yamamoto et al., 2007). Mass spectrometry and semiquantitative studies have shown that all the sirtuins are expressed in the human and non-human brain and small intestine (Sidorova-Darmos et al., 2014; Jayasena et al., 2016). In the brain, SIRT1 $(110 \mathrm{KDa})$ and SIRT2 $(37 \mathrm{KDa})$ are the most abundant and widely expressed sirtuin subtypes. SIRT1 expression is highest in the neurons of the cerebellum, hippocampus, and the hypothalamus and lowest in the spinal cord. SIRT2 is highest in the spinal cord and brain stem and is also highly expressed in the cortex, frontal lobe, hippocampus, striatum, and cerebellum. The mitochondrial sirtuins, SIRT3, SIRT4, SIRT5, are also expressed in different regions of the brain, but at lower levels than SIRT1 and SIRT2. In the brain, SIRT6 and SIRT7 are expressed at the lowest levels compared to other sirtuins. All the sirtuins, except for SIRT7, are expressed at lower levels in the small intestine than is detected in the brain. SIRT7 is the most highly expressed sirtuin in the small intestine with 10-fold higher expression than in the brain. Considering that subcellular localization of sirtuins are cell type dependent, more sampling across different cell lines and tissue types can provide information about the anatomical contribution of the lesser abundant sirtuins. Recent studies have shown that both SIRT1 and SIRT3 are expressed by neurons of the ENS (Lakhan and Kirchgessner, 2011; Bubenheimer et al., 2016). However, the role of sirtuins in ENS neurodegeneration remains unknown.

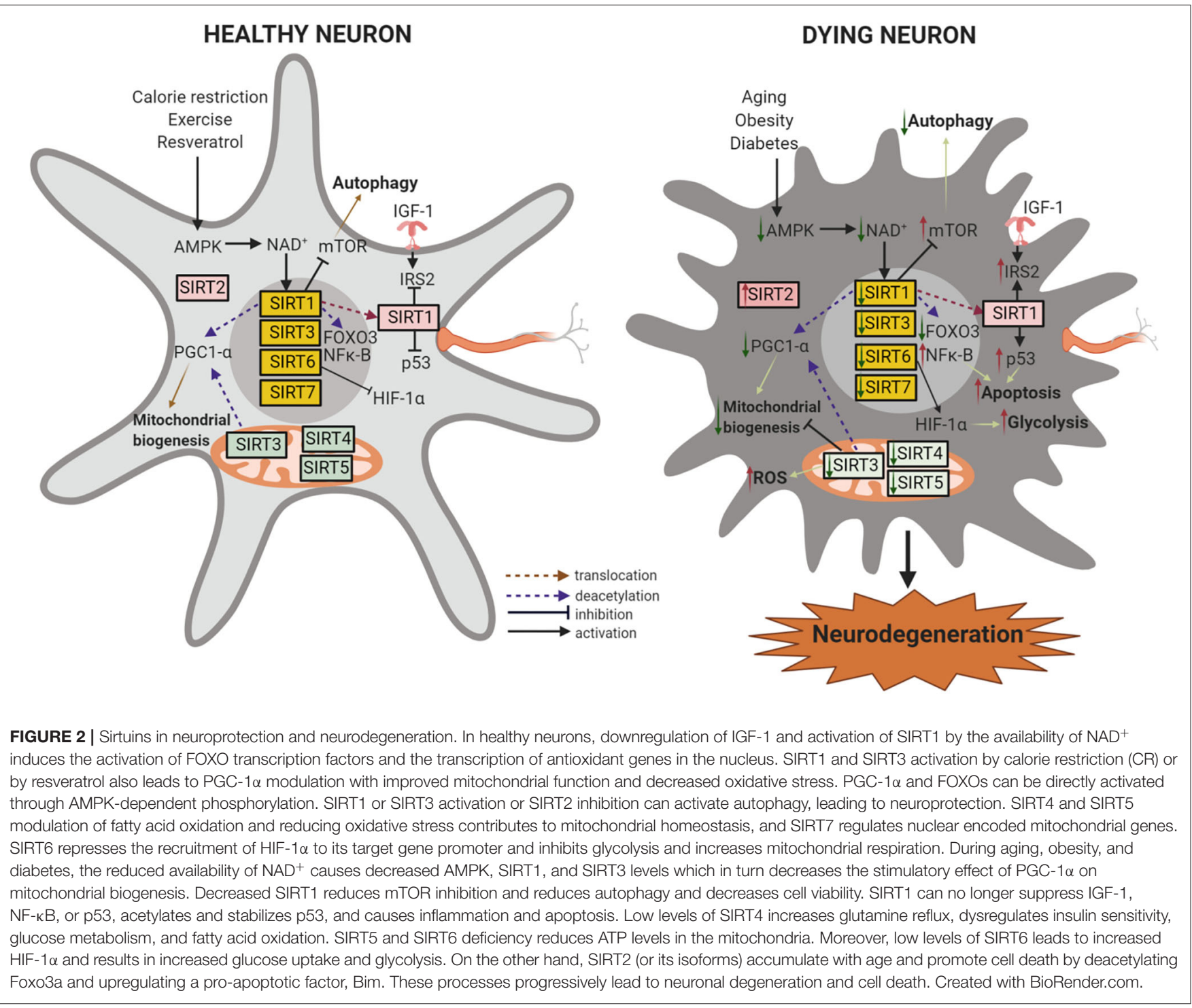




\section{ROLE OF SIRTUINS IN MODULATING NEURODEGENERATION IN THE CNS}

\section{Role of Sirtuins in Modulating Neurodegeneration Associated With Aging and Neurodegenerative Diseases}

Aging leads to damage of cellular organelles and accumulation of proteins that causes an imbalance in cellular homeostasis and accelerates neurodegeneration (Castelli et al., 2019). SIRT1 and SIRT6 levels increase and decrease respectively with age respectively despite similarities in cellular localization and their role in increasing lifespan (Lee et al., 2019). A reduction in SIRT1 activity was reported in post-mortem brain tissue of PD patients (Singh et al., 2017). SIRT1 has shown to be universally involved in multiple pathways associated with stress related to energy homeostasis and metabolism through epigenetic regulation and transcriptional modulation whereas SIRT6 is important for glucose metabolism and exerts neuroprotection from DNA damage (Ramadori et al., 2008; Zhong and Mostoslavsky, 2010). Overexpression of brain-specific SIRT1, ubiquitous overexpression of SIRT6, calorie restriction, or resveratrol, extended lifespan and prevented experimental AD amyloid neuropathology (Giblin et al., 2014). Resveratrol has been shown to inhibit the activity of a serine/threonine kinase called mammalian target of rapamycin (mTOR) which contrasts with nicotinamide, a SIRT1 antagonist enhanced mTOR activity and reduced age-induced autophagy (Ghosh et al., 2010). In neurons comprising of non-dividing cells, SIRT1 has been shown to foster DNA repair during double strand breaks and protect against genomic instability caused by aging (Oberdoerffer et al., 2008). Studies in rat brain, kidney, liver, and fat pad tissues showed that SIRT1 induced by calorie restriction maintained a DNA repair factor, Ku70 in a deacetylated state to sequester Bax from the mitochondria to attenuate apoptosis, thus shifting the balance from cell death toward cell survival (Amsel et al., 2008). SIRT1 and in some cases, SIRT2 and the signaling pathways of insulin and insulin-like growth factor-I (IGF-I), bidirectionally regulate each other (Sansone et al., 2013). IGF-1 is an important growth factor that has been shown to be important for neurogenesis and cell survival of neurons as well as inhibition of apoptosis during postnatal to adult stages (Nieto-Estevez et al., 2016). IGF-1 declines with age in the brains of humans and rodents, and treatment with IGF-1 agonists in preclinical models of $\mathrm{AD}$ and $\mathrm{PD}$ have shown to improve neuronal survival (NietoEstevez et al., 2016). Notably, SIRT1 deacetylates insulin receptor substrate 2 (IRS-2), a substrate protein for IGF-1 and activates Akt, an insulin receptor target of IGF (Sansone et al., 2013), highlighting SIRT1 importance in modulating IGF-1 signaling.

Overexpression of SIRT1 and the addition of resveratrol has shown to provide neuroprotective effects in various animal models of $\mathrm{AD}$ by reducing amyloid plaque formation and neurofibrillary tau pathology (Chen et al., 2005; Qin et al., 2006; Kim et al., 2007; Green et al., 2008; Karuppagounder et al., 2009; Min et al., 2010; Vingtdeux et al., 2010). SIRT1 was shown to target ADAM10, a retinoic acid receptor $\beta$ target and induce Notch receptor cleavage to promote non-amyloidogenic processing of amyloid precursor protein (APP), thereby promoting neurogenesis (Donmez et al., 2010). Overexpression of SIRT1 protected SH-SY5Y neuroblastoma cells from toxin induced cell death by down-regulating NF$\kappa \mathrm{B}$ and CPARP-1 and reducing phospho- $\alpha$-synuclein aggregates (Singh et al., 2017). Resveratrol acting via SIRT1/PGC-1 $\alpha$ significantly protected dopaminergic neurons in the MPTP mouse model of PD (Mudo et al., 2012). Interestingly in other studies, SIRT1 failed to protect tyrosine hydroxylase (TH)positive dopaminergic neuronal damage induced by MPTP (Kakefuda et al., 2009). SIRT2 inhibition was shown to reduce $A \beta$ production and improved cognitive performance and microtubule assembly favoring cell survival (Biella et al., 2016; Silva et al., 2017). SIRT3 expression was decreased in $\mathrm{AD}$ patient's cerebral cortex and its dysfunction led to p53-mediated mitochondrial and neuronal damage in $\mathrm{AD}$ (Lee et al., 2018). Patients with AD showed a reduction in the expression of SIRT6. Increased signs of DNA damage, cell death, and hyperphosphorylated Tau, all features of neurodegenerative diseases, were observed in SIRT6-deficient mice brain (Kaluski et al., 2017) indicating the importance of SIRT6 regulation of DNA repair and maintenance of genomic stability to keep the brain healthy (Giblin et al., 2014; Kugel and Mostoslavsky, 2014). SIRT2 has largely been found as detrimental in several neurodegenerative disorders (Gomes et al., 2015). Polymorphisms in a SIRT2 intron increased susceptibility to $\mathrm{AD}$ and its knockout and inhibition studies improved outcomes in a PD model by reducing cytoskeletal pathology and increasing autophagy (Biella et al., 2016; Guan et al., 2016). SIRT2 inhibition may have beneficial effects for PD by rescuing $\alpha$-synuclein mediated toxicity (Outeiro et al., 2007; de Oliveira et al., 2017). SIRT3 has been demonstrated to protect cortical neurons from various types of stress by increasing mitochondrial antioxidant capacity (Cheng et al., 2016). Mice with SIRT3 deletion was shown to have reduced neuron number, synaptic plasticity, and poor remote memory, thereby dramatically increasing neuronal vulnerability (Kim et al., 2011; Dai et al., 2014). SIRT3 and SIRT5 have the largest protective effects on neurons of the nigrostriatal pathway within the brain (Liu et al., 2015a,b). SIRT5 displays a protective role against MPTP-induced nigrostriatal dopaminergic degeneration by preserving mitochondrial antioxidant capacity (Liu et al., 2015b). Resveratrol and another polyphenol quercetin in mice models were shown to prevent motor neuron degeneration and polyglutamine-induced cell death in striatal neurons characteristic of motor neuron disorders such as amyotrophic lateral sclerosis (ALS), spinal muscular atrophy (SMA), and Huntington Disease (HD), respectively (Bhullar and Rupasinghe, 2013; Lazo-Gomez and Tapia, 2017). SIRT6 and SIRT7 were shown to deacetylate the nucleolar protein, nucleophosmin (NPM1) that is involved in DNA repair to regulate aging (Wu et al., 2018). 


\section{Role of Sirtuins in Modulating Neurodegeneration Associated With Obesity and Diabetes}

Increased SIRT1 expression in dorsal root ganglion (DRG) neurons was shown to rescue mice from peripheral neuropathy induced by a high fat diet (HFD) (Chandrasekaran et al., 2019). SIRT1 is also regulated by the hypothalamus/pituitary axis that receives inputs related to nutrients and adiposity (Toorie and Nillni, 2014). SIRT1 inhibition in the hypothalamus, via the acetylation of FOXO1, increased neurons that express proopiomelanocortin and agouti-related peptide. These neurons produce satiety peptides to inhibit food intake after feeding and increase food intake in response to fasting and CR, respectively. This resulted in reduced feeding and body weight gain (Dietrich et al., 2010). This established the role of SIRT1 as an important regulator of nutrient sensing in the neural circuits that govern central and peripheral networks. SIRT3 deletion in the hippocampus of mice fed a high fat diet was shown to cause oxidative stress and impaired cognition (Tyagi et al., 2018). This was alleviated by SIRT3-mediated aerobic interval training that upregulated the antioxidant manganese superoxide dismutase (MnSOD) and inhibited neuronal apoptosis (Shi et al., 2018). SIRT6 and SIRT7 have been shown to be important for glucose production and metabolism. Studies in SIRT6 deleted mice have shown that SIRT6 deacetylates histone 3 lysine 9 (H3K9) to repress hypoxia-inducible factor, HIF- $1 \alpha$, in the promoter of Glucose transporter type1 (GLUT1) and Pyruvate Dehydrogenase Kinase, Isoenzyme 1 (PDK1) enzymes to facilitate glucose metabolism (Zhong et al., 2010). Knockout studies have shown that SIRT7 is an epigenetic modulator of glucose metabolism that regulates ribosomal biogenesis and promotes mitochondrial biogenesis via PRMT6 methylation and connects it to glucose availability in an AMPK dependent manner (Yan et al., 2018). These studies demonstrate the important functions carried out by SIRT6 and SIRT7 to regulate glucose homeostasis. The pathways relevant to neurodegeneration and modulated by sirtuins are summarized in Figure 2.

\section{ROLE OF SIRTUINS IN REGULATION OF NEURODEGENERATION IN THE ENS}

The ENS develops from enteric neural crest cells, a multipotent cell population that originates in the neural tube and migrates across the embryo to reach the developing intestine, where it proliferates and differentiates into enteric neurons and glia (Nagy and Goldstein, 2017). These neural progenitors eventually differentiate into several distinct neuronal subtypes that eventually comprise both the myenteric and submucosal plexi (Furness, 2012). Comparative studies between the intestines of young ( 3 months old) and old ( $>24$ months) mice $(n=6)$ has shown that aging reduced the number of intestinal stem cells (ISCs) in vivo as well as the formation of intestinal organoids from the ISCs ex vivo that gives rise to differentiated cells of the gut (Igarashi et al., 2019). The plexuses are areas that are vulnerable to neurodegeneration from aging and high-fat or high sugar induced diets (Lakhan and Kirchgessner, 2011;
Stenkamp-Strahm et al., 2015; McMenamin et al., 2018). Sirtuins are widely expressed in the gut (Figure 3, Zeisel et al., 2018) and neurons in the murine colon show immunoreactivity to SIRT1 where they localize to the nucleus, in the myenteric plexus (Lakhan and Kirchgessner, 2011). A knockout of SIRT1 in the gut of mice was reported to increase gastric emptying and intestinal contraction with suppressed villous apoptosis and increased crypt proliferation (Wang et al., 2012). This could indicate an altered cholinergic neuronal function. In the same study, the genes ghrelin and Period Circadian Clock 2 Gene, Per2, which regulate food intake and circadian rhythm respectively (Yannielli et al., 2007; Kim et al., 2018), were also found to be increased in the stomach and hypothalamus, implying a role for SIRT1 in regulating GI functions controlled by the circadian systems. Treatment of aged mice with SIRT1-dependent NAD ${ }^{+}$ precursor, nicotinamide riboside restored ISC number and its functional defects in aged mice in vivo (Igarashi et al., 2019) but this was blocked by SIRT1 inhibitor EX527, suggesting a role for SIRT1 activators or precursors in maintaining the intestine during aging. Similar to the role of astrocytes in the CNS, enteric glia modulates the ENS by regulating motility and secretion by sensing neuronal reflexes by virtue of its plasticity (Gulbransen and Christofi, 2018). The glia is also important for epithelial health, and ablation of glia in transgenic mice has shown to cause alterations in motor and mucosal activity, resulting in intestinal inflammation, myenteric degeneration, hemorrhage, and necrosis (Aube et al., 2006). Obesity in the gut is characterized by persistent low-grade inflammation with alterations in gut motility (Hotamisligil, 2006). Experimental data show that gut inflammation, even if mild, could lead to persistent changes in GI nerve and smooth muscle function, resulting in dysmotility, hypersensitivity, and dysfunction (Mawe et al., 2009; Lakhan and Kirchgessner, 2010). Thus, the breakdown of mucosal barrier function as observed in obesity could cause alterations in the patterns of gut motility, abnormal secretion, and changes in visceral sensation that contributes to gastrointestinal symptoms. Whether the changes in GI motility observed in many obese patients are due to inflammationrelated changes in the properties of enteric neurons is yet to be explored. Intestinal epithelium-specific knockout of SIRT1 in aged mice induced spontaneous inflammation and tissue damage in the colon and increased their susceptibility to colitis (Wellman et al., 2017). Increased proinflammatory cytokines and leukocyte infiltration, decreased colon lengths, elevated levels of LPS, and increased expression levels of anti-microbial proteins was observed in the SIRT1 KO mice compared to their agematched controls. SIRT1 induced by resveratrol administration to rats has shown to be protective against acute intestinal inflammation from colitis by downregulating inflammation via NF-кB (Larrosa et al., 2009; Hofseth et al., 2010). In an experimental model of ileitis, oral administration of resveratrol increased the survival of resveratrol-treated mice after exposure to T. gondii, decreased mRNA expression of pro-inflammatory cytokine-IL-6, and increased the mRNA expression of antiinflammatory cytokine-IL-10 in the ileum, compared to the control group (Bereswill et al., 2010). These studies highlight SIRT1 as a potential target in inflammatory diseases of the 


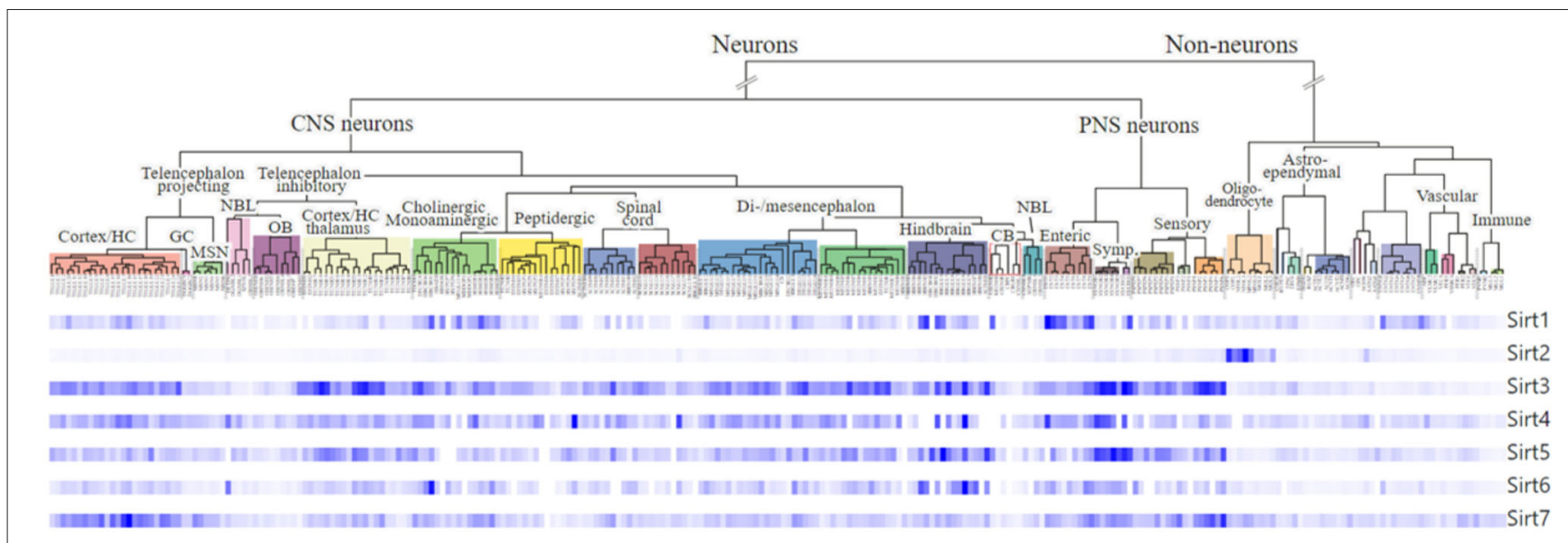

FIGURE 3 | Expression and cellular localization of sirtuins in the neurons of the mouse CNS and the ENS. Dendrogram showing gene expression of all the seven sirtuins in cell populations generated by single-cell RNA sequencing (scRNA-seq) in the central nervous system (CNS) neurons and the enteric neurons in the peripheral nervous system (PNS) using data from Zeisel et al. (2018). The plots were generated using the online database, Mouse Brain Atlas http://mousebrain.org/ genesearch.html.

intestine. Studies in mice and cell cultures have shown that SIRT3 protects cortical and dopaminergic neurons from oxidative stress by regulating mitochondrial homeostasis (Kim et al., 2011; Dai et al., 2014; Shi et al., 2017). Unlike its protective role in the CNS, a SIRT3 knockout in mice exposed to dinitrobenzene sulfonic acid mode of colonic inflammation was shown to not have any effects in counteracting oxidative stress or the susceptibility of myenteric neurons to inflammation (Bubenheimer et al., 2016). Further research is required to explore the role of sirtuin proteins in enteric neurobiology during normal and inflamed states.

\section{ROLE OF SIRTUINS AS MODULATORS OF GUT MICROBIOTA ALONG THE MICROBIOTA-GUT-BRAIN AXIS}

The gut microbiota regulates many metabolic processes in addition to host energy homeostasis by taking part in the gut-brain crosstalk, a complex bidirectional communication system. This is mediated by gut microbiota produced signaling molecules like short-chain fatty acids (SCFAs: acetate, butyrate and propionate), lipopolysaccharide (LPS), 5-hydroxytryptamine (5-HT), biogenic amines (dopamine, norepinephrine), glutamate and $\gamma$-aminobutyric acid (GABA) (Nicholson et al., 2012; O’Mahony et al., 2015; Koh et al., 2016; Mazzoli and Pessione, 2016; Bhattarai et al., 2017; Sudo, 2019). The gut microbiota metabolites affect brain activity either through blood circulation or acting via vagus nerve afferent fibers, while vagal efferent fibers regulate gut permeability and inflammation influencing gut functions (Bonaz et al., 2018). Enteroendocrine cells (EECs) are in direct contact with the luminal contents and mediate the communication between gut microbiota and enteric innervations. They produce hormones and peptides including serotonin, ghrelin, cholecystokinin, glucagon-like peptide-1 (GLP-1), peptide YY (PYY) and pancreatic polypeptide whose receptors are expressed in gut enteric neurons, vagal afferents, brain stem, and hypothalamus (De Silva and Bloom, 2012; Richards et al., 2014). EECs maintain gut homeostasis by regulating food intake and insulin secretion (Gribble and Reimann, 2016). SCFA stimulate the secretion of the leptin, GLP-1, and peptide YY(3-36), and lower body weight thereby contributing to gut-brain activation (Xiong et al., 2004; Tazoe et al., 2008; Tolhurst et al., 2012). The gut-brain bidirectional communication happens largely through the ENS which along with commensal microflora and immune cells, plays an important role in regulating intestinal epithelial barrier function (Snoek et al., 2010). Dysbiosis, an imbalance in the gut microbial community is linked to several metabolic diseases such as obesity, type-2 diabetes mellitus and inflammatory bowel diseases (Castaner et al., 2018; Zuo and Ng, 2018; Sharma and Tripathi, 2019). It is often associated with a reduction in the Bacteroidetes:Firmicutes ratio and increased gut permeability (Tremaroli and Backhed, 2012; Zuo and Ng, 2018; Sharma and Tripathi, 2019) with low-grade gut inflammation. Considerable shifts in human gut microbiota composition have been observed in several CNS disorders including neurodegeneration (Fung et al., 2017). Gut dysbiosis play an important role in modulating the gut-brain axis. An impaired gut barrier facilitate entry of bacterial endotoxins like LPS into the blood circulation, elicit inflammatory response, causing metabolic endotoxemia that eventually leads to insulin resistance and weight gain (van Olden et al., 2015). This impairment can also affect the blood brain barrier promoting neuro-inflammation and neurodegeneration including anxiety and depression (Liu, 2017).

Over recent years, accumulating evidence has suggested the role of sirtuins in obesity, diabetes, and various age-related neurodegenerative diseases by modulating gut microbiota at times, implicating the importance of gut-brain axis connections. Much of the studies involving sirtuins and gut microbiota have been done using resveratrol, which activates SIRT1. Resveratrol is thought to possess antibacterial activity against opportunistic pathogens of the digestive tract like Escherichia coli, Salmonella 
enterica, and Enterococcus faecalis (Paulo et al., 2010), thereby contributing to maintenance of normal gut bacterial species. The epithelial barrier integrity and function is regulated by resveratrol by increasing the expression of intestinal tight junction proteins such as tight junction protein 2, occludin, and claudin 4 (Etxeberria et al., 2015; Ling et al., 2016; Wang et al., 2016). Resveratrol up-regulated SIRT1 display anti-inflammatory role in the gut by decreasing immune responses (Th1-type) and preventing bacterial translocation by maintaining gut barrier function (Bereswill et al., 2010), which is compromised in obesity (Cani and Delzenne, 2010). Resveratrol functions by modulating the composition of the gut microbiota (Chen et al., 2016; Komaroff, 2017). Mice studies have suggested that resveratrol can influence the relation between gut microbiota, diet, and obesity (Clarke et al., 2012; Komaroff, 2017) either by changing the expression of genes involved in central regulation of body weight homeostasis like fasting-induced adipose factor (Fiaf) or mTOR (Kim et al., 2010; Qiao et al., 2014; Jung et al., 2016), or by reversing the gut microbial dysbiosis caused by a high-fat diet by modifying the relative Bacteroidetes: Firmicutes ratio (Qiao et al., 2014; Sung et al., 2017). A recent study has shown that fecal microbiota transplantation from resveratrol treated mice to HFD mice reversed weight gain and improved gut microbiota composition and intestinal permeability (Wang et al., 2020). SIRT1 deficiency in the intestinal epithelium as studied with SIRT1 intestinal knock out mice, resulted in altered gut microbial composition, increased intestinal inflammation, and susceptibility to colitis implicating SIRT1 importance in maintaining intestinal tissue homeostasis through modulation of the gut microbiota (Wellman et al., 2017). In colonic biopsies from patients with inflammatory bowel disease (IBD), SIRT1 was downregulated by TNF- $\alpha$ and IL-21 in the mucosa (Caruso et al., 2014). Moreover, incubation with a SIRT1 agonist, Cay10591 reduced the acetylation of NF-kBp65 and suppressed the inflammatory cytokine production in the colon as seen in IBD. It also ameliorated experimental colitis induced in mice by reducing LPS-induced TNF- $\alpha$ production whereas a SIRT1 antagonist, Ex527 aggravated the same. On the contrary, another experimental study on mice and worms with an intestinal deletion of SIRT1 increased Paneth and goblet cell number and upregulated anti-bacterial peptides such as lysozyme and cryptidines resulting in a rearrangement of the gut microbiota, thus protecting them from colitis-induced colorectal cancer (Lo Sasso et al., 2014). The direct effects of resveratrol on SIRT1 or sirtuin activation in general is not completely conclusive as resveratrol as well as other sirtuin activators have many molecular targets that acts via diverse pathways on different sirtuin isoforms, depending on the substrate sequence and the type of acyl modification (Athar et al., 2009; Gertz et al., 2012; Britton et al., 2015; Gomes et al., 2019). With regards to SIRT1, resveratrol either directly binds and activates SIRT1 or increases the intracellular pool of $\mathrm{NAD}^{+}$via phosphorylation of AMPK by serine-threonine liver kinase B1 (LKB1) or calcium/calmodulin kinase kinase- $\beta(\mathrm{CaMKK} \beta)$ kinases on its catalytic $\alpha$-subunit, that can be utilized by SIRT1 (Lan et al., 2017).

The aberrant microbiota to CNS pathway is thought to result in the formation of insoluble protein aggregates within neurons in neurodegenerative disorders (Quigley, 2017). Toxic accumulation of misfolded and aggregated $\alpha$-synuclein protein, Lewy bodies, is seen in both CNS and ENS of Parkinson's disease (PD) patients (Beach et al., 2010). Gram-negative bacteria in these patients are abundant producing LPS which contributes to $\alpha$-synuclein aggregation leading to dopaminergic neuronal death, thereby causing motor impairments through inflammatory pathways (Sharma and Nehru, 2015). Using mice that overexpress $\alpha$ Syn, it is shown that gut microbiota promotes motor deficits and microglia activation. $\alpha$ Syn aggregation results in progression of the disease (Sampson et al., 2016). Studies show the correlation between increased gut permeability due to endotoxin exposure and alpha-synuclein staining in early Parkinson's disease (Forsyth et al., 2011). PD is frequently associated with impaired gastric motility (Fasano et al., 2015). Several studies have supported the hypothesis that PD may initiate in the gut since GI dysfunctions appear many years before motor impairments suggesting spread of $\alpha$-syn pathology from the ENS to the CNS. Alzheimer's disease (AD) is characterized by an accumulation of protein aggregates composed of amyloid$\beta$ peptide $(A \beta)$ and tau in CNS tissues impairing cognitive function and the pathogenesis is believed to be associated with increased permeability of the gut and blood-brain barrierinduced by microbiota dysbiosis (Jiang C. et al., 2017). Gut bacteria can secrete large amounts of amyloids and LPS which modulates the signaling pathways that lead to neurodegeneration and $\mathrm{AD}$ pathogenesis, as well as inflammatory response to $\mathrm{A} \beta$ accumulation in CNS (Pistollato et al., 2016). Amyloid precursor protein (APP) from which $A \beta$ is derived, is expressed in the ENS suggesting its role in the pathogenesis of AD (Arai et al., 1991). Studies with transgenic mice overexpressing APP has shown progressive accumulation of $A \beta$ within enteric neurons leading to a decreased number of enteric neurons, dysmotility and intestinal inflammation (Semar et al., 2013; Puig et al., 2015), implying that ENS dysfunction could occur in AD.

The concept of microbiota-gut-brain axis is extensively studied, with an emphasis being on the gut dysbiosis in the onset and/or progression of several metabolic diseases such as obesity, type- 2 diabetes mellitus, and the most commonly studied forms of neurodegeneration, such as $\mathrm{AD}$ and $\mathrm{PD}$. This review examines scientific literature addressing the possible role of sirtuins in regulating this axis thereby targeting themselves as molecules of importance therapeutically. Each sirtuin has different targets, located in different subcellular locations, and might function quite differently. Therefore, it is extremely important to develop selective activators or inhibitors that target a specific sirtuin. Sirtuins are known to modulate gut microbiota. It is critical for future studies to clarify using sirtuins as interventions to correct dysbiosis, which may provide safe and effective treatments to slow or halt the progression of clinical disorders.

\section{FUTURE PERSPECTIVES}

This review offers a consolidated overview of sirtuins and their important functions in modulating neurodegeneration in the CNS and the ENS. The precise functions of sirtuins 
are still unclear, but they seem to be important players in age- and metabolism-associated neurodegeneration. Therefore, elucidating the molecular roles of sirtuins may enable the development of novel strategies for intervention in neurodegenerative diseases. Inhibition of SIRT2 while overexpressing SIRT1 is a potential strategy that could be used to treat certain age-related neurodegenerative diseases. The connection between sirtuins and dietary restriction also warrants further investigation on the precise role of sirtuins. However, the beneficial effect of dietary restriction on aging and various metabolic disorders is dependent on the activation of SIRT1 and can be mimicked by resveratrol. SIRT1 via resveratrol has shown neuroprotective effects against acute inflammation induced by colitis and are expressed by enteric neurons suggesting that it might help in gut motility and secretion. This could be a promising and previously unrecognized role of enteric sirtuins, especially SIRT1, in regulating energy homeostasis. Moreover, activation of enteric sirtuin pathways could offer a therapeutic approach to treating diabetes- and obesity-related gut dysfunction as well as age-induced neurodegeneration. Using genetically engineered reporter mice that illuminate the entire

\section{REFERENCES}

Al-Goblan, A. S., Al-Alfi, M. A., and Khan, M. Z. (2014). Mechanism linking diabetes mellitus and obesity. Diabetes Metab. Syndr. Obes. 7, 587-591. doi: 10.2147/DMSO.S67400

Amsel, A. D., Rathaus, M., Kronman, N., and Cohen, H. Y. (2008). Regulation of the proapoptotic factor bax by Ku70-dependent deubiquitylation. Proc. Natl. Acad. Sci. U.S.A. 105, 5117-5122. doi: 10.1073/pnas.0706700105

Anderson, K. A., Madsen, A. S., Olsen, C. A., and Hirschey, M. D. (2017). Metabolic control by sirtuins and other enzymes that sense $\mathrm{NAD}(+), \mathrm{NADH}$, or their ratio. Biochim. Biophys. Acta 1858, 991-998. doi: 10.1016/j.bbabio.2017.09.005

Arai, H., Lee, V. M., Messinger, M. L., Greenberg, B. D., Lowery, D. E., and Trojanowski, J. Q. (1991). Expression patterns of beta-amyloid precursor protein (beta-APP) in neural and nonneural human tissues from alzheimer's disease and control subjects. Ann. Neurol. 30, 686-693. doi: 10.1002/ana.410300509

Arnold, S. E., Arvanitakis, Z., Macauley-Rambach, S. L., Koenig, A. M., Wang, H. Y., Ahima, R. S., et al. (2018). Brain insulin resistance in type 2 diabetes and alzheimer disease: concepts and conundrums. Nat. Rev. Neurol. 14, 168-181. doi: 10.1038/nrneurol.2017.185

Athar, M., Back, J. H., Kopelovich, L., Bickers, D. R., and Kim, A. L. (2009). Multiple molecular targets of resveratrol: anti-carcinogenic mechanisms. Arch. Biochem. Biophys. 486, 95-102. doi: 10.1016/j.abb.2009.01.018

Aube, A. C., Cabarrocas, J., Bauer, J., Philippe, D., Aubert, P., Doulay, F., et al. (2006). Changes in enteric neurone phenotype and intestinal functions in a transgenic mouse model of enteric glia disruption. Gut 55, 630-637. doi: 10.1136/gut.2005.067595

Beach, T. G., Adler, C. H., Sue, L. I., Vedders, L., Lue, L., White Iii, C. L., et al. (2010). Multi-organ distribution of phosphorylated alpha-synuclein histopathology in subjects with Lewy body disorders. Acta Neuropathol. 119, 689-702. doi: 10.1007/s00401-010-0664-3

Becker, L., Nguyen, L., Gill, J., Kulkarni, S., Pasricha, P. J., and Habtezion, A. (2018). Age-dependent shift in macrophage polarisation causes inflammationmediated degeneration of enteric nervous system. Gut 67, 827-836. doi: 10.1136/gutjnl-2016-312940

Bemis, J. E., Vu, C. B., Xie, R., Nunes, J. J., Ng, P. Y., Disch, J. S., et al. (2009). Discovery of oxazolo[4,5-b]pyridines and related heterocyclic analogs as novel SIRT1 activators. Bioorg. Med. Chem. Lett. 19, 2350-2353. doi: 10.1016/j.bmcl.2008.11.106
ENS (Jiang Y. et al., 2017), the effects of sirtuins on different neuronal subtypes can be better visualized and investigated when compared to traditional immunohistochemistry. Further research and identification of novel or repurposing of previously known small molecule activators and inhibitors of sirtuins could have a potential impact in the therapy of neurodegenerative disorders.

\section{AUTHOR CONTRIBUTIONS}

PC and SS designed the structure and contents of the review. PC, AV, and DA wrote and edited the manuscript. PC, AV, GL, SM, and SS provided critical revisions to the article. All authors contributed to the article and approved the submitted version.

\section{FUNDING}

This work was supported by U.S. National Institutes of Health (NIH) grants R01DK080684 (SS) and VA Research and Development Merit Review Award \# BX000136-12 (SS).

Bereswill, S., Munoz, M., Fischer, A., Plickert, R., Haag, L. M., Otto, B., et al. (2010). Anti-inflammatory effects of resveratrol, curcumin and simvastatin in acute small intestinal inflammation. PLoS ONE 5:e15099. doi: 10.1371/journal.pone.0015099

Bhattarai, Y., Schmidt, B. A., Linden, D. R., Larson, E. D., Grover, M., Beyder, A., et al. (2017). Human-derived gut microbiota modulates colonic secretion in mice by regulating 5-HT3 receptor expression via acetate production. Am. J. Physiol. Gastrointest. Liver Physiol. 313, G80-G87. doi: 10.1152/ajpgi.00448.2016

Bhullar, K. S., and Rupasinghe, H. P. (2013). Polyphenols: multipotent therapeutic agents in neurodegenerative diseases. Oxid. Med. Cell. Longev. 2013:891748. doi: 10.1155/2013/891748

Biella, G., Fusco, F., Nardo, E., Bernocchi, O., Colombo, A., Lichtenthaler, S. F., et al. (2016). Sirtuin 2 inhibition improves cognitive performance and acts on amyloid-beta protein precursor processing in two alzheimer's disease mouse models. J. Alzheimers Dis. 53, 1193-1207. doi: 10.3233/JAD-151135

Bischof, G. N., and Park, D. C. (2015). Obesity and aging: consequences for cognition, brain structure, and brain function. Psychosom. Med. 77, 697-709. doi: 10.1097/PSY.0000000000000212

Bonaz, B., Bazin, T., and Pellissier, S. (2018). The vagus nerve at the interface of the microbiota-gut-brain axis. Front. Neurosci. 12:49. doi: 10.3389/fnins.2018.00049

Borra, M. T., Smith, B. C., and Denu, J. M. (2005). Mechanism of human SIRT1 activation by resveratrol. J. Biol. Chem. 280, 17187-17195. doi: 10.1074/jbc.M501250200

Britton, R. G., Kovoor, C., and Brown, K. (2015). Direct molecular targets of resveratrol: identifying key interactions to unlock complex mechanisms. Ann. N. Y. Acad. Sci. 1348, 124-133. doi: 10.1111/nyas.12796

Bubenheimer, R. K., Brown, I. A., Fried, D. E., McClain, J. L., and Gulbransen, B. D. (2016). Sirtuin-3 is expressed by enteric neurons but it does not play a major role in their regulation of oxidative stress. Front. Cell. Neurosci. 10:73. doi: $10.3389 /$ fncel.2016.00073

Cani, P. D., and Delzenne, N. M. (2010). Involvement of the gut microbiota in the development of low grade inflammation associated with obesity: focus on this neglected partner. Acta Gastroenterol. Belg. 73, 267-269.

Canto, C., Sauve, A. A., and Bai, P. (2013). Crosstalk between poly(ADP-ribose) polymerase and sirtuin enzymes. Mol. Aspects Med. 34, 1168-1201. doi: 10.1016/j.mam.2013. 01.004 
Carabotti, M., Scirocco, A., Maselli, M. A., and Severi, C. (2015). The gut-brain axis: interactions between enteric microbiota, central and enteric nervous systems. Ann. Gastroenterol. 28, 203-209.

Caruso, R., Marafini, I., Franze, E., Stolfi, C., Zorzi, F., Monteleone, I., et al. (2014). Defective expression of SIRT1 contributes to sustain inflammatory pathways in the gut. Mucosal. Immunol. 7, 1467-1479. doi: 10.1038/mi.2014.35

Castaner, O., Goday, A., Park, Y. M., Lee, S. H., Magkos, F., Shiow, S. T. E., et al. (2018). The gut microbiome profile in obesity: a systematic review. Int. J. Endocrinol. 2018:4095789. doi: 10.1155/2018/4095789

Castelli, V., Benedetti, E., Antonosante, A., Catanesi, M., Pitari, G., Ippoliti, R., et al. (2019). Neuronal cells rearrangement during aging and neurodegenerative disease: metabolism, oxidative stress and organelles dynamic. Front. Mol. Neurosci. 12:132. doi: 10.3389/fnmol.2019.00132

Chandrasekaran, K., Anjaneyulu, M., Choi, J., Kumar, P., Salimian, M., Ho, C. Y., et al. (2019). Role of mitochondria in diabetic peripheral neuropathy: influencing the $\mathrm{NAD}(+)$-dependent SIRT1-PGC-1alpha-TFAM pathway. Int. Rev. Neurobiol. 145, 177-209. doi: 10.1016/bs.irn.2019.04.002

Chandrasekharan, B., and Srinivasan, S. (2007). Diabetes and the enteric nervous system. Neurogastroenterol. Motil. 19, 951-960. doi: 10.1111/j.1365-2982.2007.01023.x

Chen, F., Wen, Q., Jiang, J., Li, H. L., Tan, Y. F., Li, Y. H., et al. (2016). Could the gut microbiota reconcile the oral bioavailability conundrum of traditional herbs? J. Ethnopharmacol. 179, 253-264. doi: 10.1016/j.jep.2015. 12.031

Chen, J., Zhou, Y., Mueller-Steiner, S., Chen, L. F., Kwon, H., Yi, S., et al. (2005). SIRT1 protects against microglia-dependent amyloid-beta toxicity through inhibiting NF-kappaB signaling. J. Biol. Chem. 280, 40364-40374. doi: 10.1074/jbc.M509329200

Cheng, A., Yang, Y., Zhou, Y., Maharana, C., Lu, D., Peng, W., et al. (2016). Mitochondrial SIRT3 mediates adaptive responses of neurons to exercise and metabolic and excitatory challenges. Cell Metab. 23, 128-142. doi: 10.1016/j.cmet.2015.10.013

Clarke, S. F., Murphy, E. F., Nilaweera, K., Ross, P. R., Shanahan, F., O’Toole, P. W., et al. (2012). The gut microbiota and its relationship to diet and obesity: new insights. Gut Microbes 3, 186-202. doi: 10.4161/gmic. 20168

Coll, A. P., Farooqi, I. S., and O'Rahilly, S. (2007). The hormonal control of food intake. Cell 129, 251-262. doi: 10.1016/j.cell.2007.04.001

Cooke, H. J. (2000). Neurotransmitters in neuronal reflexes regulating intestinal secretion. Ann. N. Y. Acad. Sci. 915, 77-80. doi: 10.1111/j.1749-6632.2000.tb05225.x

Dai, S. H., Chen, T., Wang, Y. H., Zhu, J., Luo, P., Rao, W., et al. (2014). Sirt3 protects cortical neurons against oxidative stress via regulating mitochondrial $\mathrm{Ca}^{2+}$ and mitochondrial biogenesis. Int. J. Mol. Sci. 15, 14591-14609. doi: 10.3390/ijms150814591

de Oliveira, R. M., Vicente Miranda, H., Francelle, L., Pinho, R., Szego, E. M., Martinho, R., et al. (2017). The mechanism of sirtuin 2-mediated exacerbation of alpha-synuclein toxicity in models of parkinson disease. PLoS Biol. 15:e2000374. doi: 10.1371/journal.pbio.2000374

De Silva, A., and Bloom, S. R. (2012). Gut hormones and appetite control: a focus on PYY and GLP-1 as therapeutic targets in obesity. Gut Liver 6, 10-20. doi: $10.5009 /$ gnl.2012.6.1.10

Dietrich, M. O., Antunes, C., Geliang, G., Liu, Z. W., Borok, E., Nie, Y., et al. (2010). Agrp neurons mediate Sirtl's action on the melanocortin system and energy balance: roles for Sirt1 in neuronal firing and synaptic plasticity. J. Neurosci. 30, 11815-11825. doi: 10.1523/JNEUROSCI.2234-10.2010

Donmez, G., Wang, D., Cohen, D. E., and Guarente, L. (2010). SIRT1 suppresses beta-amyloid production by activating the alphasecretase gene ADAM10. Cell 142, 320-332. doi: 10.1016/j.cell.2010. 06.020

Duan, W. (2013). Sirtuins: from metabolic regulation to brain aging. Front. Aging Neurosci. 5:36. doi: 10.3389/fnagi.2013.00036

Elobeid, A., Libard, S., Leino, M., Popova, S. N., and Alafuzoff, I. (2016). Altered proteins in the aging brain. J. Neuropathol. Exp. Neurol. 75, 316-325. doi: 10.1093/jnen/nlw002

Etxeberria, U., Arias, N., Boque, N., Macarulla, M. T., Portillo, M. P., Martinez, J. A., et al. (2015). Reshaping faecal gut microbiota composition by the intake of trans-resveratrol and quercetin in high-fat sucrose diet-fed rats. J. Nutr. Biochem. 26, 651-660. doi: 10.1016/j.jnutbio.2015.01.002
Fasano, A., Visanji, N. P., Liu, L. W., Lang, A. E., and Pfeiffer, R. F. (2015) Gastrointestinal dysfunction in parkinson's disease. Lancet Neurol. 14, 625-639. doi: 10.1016/S1474-4422(15)00007-1

Forny-Germano, L., De Felice, F. G., and Vieira, M. (2018). The role of leptin and adiponectin in obesity-associated cognitive decline and alzheimer's disease. Front. Neurosci. 12:1027. doi: 10.3389/fnins.2018.01027

Forsyth, C. B., Shannon, K. M., Kordower, J. H., Voigt, R. M., Shaikh, M., Jaglin, J. A., et al. (2011). Increased intestinal permeability correlates with sigmoid mucosa alpha-synuclein staining and endotoxin exposure markers in early parkinson's disease. PLoS ONE 6:e28032. doi: 10.1371/journal.pone.0028032

Fung, T. C., Olson, C. A., and Hsiao, E. Y. (2017). Interactions between the microbiota, immune and nervous systems in health and disease. Nat. Neurosci. 20, 145-155. doi: 10.1038/nn.4476

Furness, J. B. (2012). The enteric nervous system and neurogastroenterology. Nat. Rev. Gastroenterol. Hepatol. 9, 286-294. doi: 10.1038/nrgastro.2012.32

Gamage, P. P., Ranson, R. N., Patel, B. A., Yeoman, M. S., and Saffrey, M. J. (2013). Myenteric neuron numbers are maintained in aging mouse distal colon. Neurogastroenterol. Motil. 25, e495-e505. doi: 10.1111/nmo.12114

Gertz, M., Nguyen, G. T., Fischer, F., Suenkel, B., Schlicker, C., Franzel, B., et al. (2012). A molecular mechanism for direct sirtuin activation by resveratrol. PLoS ONE 7:e49761. doi: 10.1371/journal.pone.0049761

Ghosh, H. S., McBurney, M., and Robbins, P. D. (2010). SIRT1 negatively regulates the mammalian target of rapamycin. PLoS ONE 5:e9199. doi: 10.1371/journal.pone.0009199

Giblin, W., Skinner, M. E., and Lombard, D. B. (2014). Sirtuins: guardians of mammalian healthspan. Trends Genet. 30, 271-286. doi: 10.1016/j.tig.2014.04.007

Gomes, O. A., de Souza, R. R., and Liberti, E. A. (1997). A preliminary investigation of the effects of aging on the nerve cell number in the myenteric ganglia of the human colon. Gerontology 43, 210-217. doi: 10.1159/000213852

Gomes, P., Fleming Outeiro, T., and Cavadas, C. (2015). Emerging role of sirtuin 2 in the regulation of mammalian metabolism. Trends Pharmacol. Sci. 36, 756-768. doi: 10.1016/j.tips.2015.08.001

Gomes, P., Leal, H., Mendes, A. F., Reis, F., and Cavadas, C. (2019). Dichotomous sirtuins: implications for drug discovery in neurodegenerative and cardiometabolic diseases. Trends Pharmacol. Sci. 40, 1021-1039. doi: 10.1016/j.tips.2019.09.003

Green, K. N., Steffan, J. S., Martinez-Coria, H., Sun, X., Schreiber, S. S., Thompson, L. M., et al. (2008). Nicotinamide restores cognition in alzheimer's disease transgenic mice via a mechanism involving sirtuin inhibition and selective reduction of Thr231-phosphotau. J. Neurosci. 28, 11500-11510. doi: 10.1523/JNEUROSCI.3203-08.2008

Gribble, F. M., and Reimann, F. (2016). Enteroendocrine cells: chemosensors in the intestinal epithelium. Annu. Rev. Physiol. 78, 277-299. doi: 10.1146/annurev-physiol-021115-105439

Guan, Q., Wang, M., Chen, H., Yang, L., Yan, Z., and Wang, X. (2016). Agingrelated 1-methyl-4-phenyl-1,2,3,6-tetrahydropyridine-induced neurochemial and behavioral deficits and redox dysfunction: improvement by AK-7. Exp. Gerontol. 82, 19-29. doi: 10.1016/j.exger.2016.05.011

Guarente, L. (2013). Calorie restriction and sirtuins revisited. Genes Dev. 27, 2072-2085. doi: 10.1101/gad.227439.113

Gulbransen, B. D., and Christofi, F. L. (2018). Are we close to targeting enteric glia in gastrointestinal diseases and motility disorders? Gastroenterology 155, 245-251. doi: 10.1053/j.gastro.2018.06.050

Hanani, M., Fellig, Y., Udassin, R., and Freund, H. R. (2004). Age-related changes in the morphology of the myenteric plexus of the human colon. Auton. Neurosci. 113, 71-78. doi: 10.1016/j.autneu.2004.05.007

Hildreth, K. L., Van Pelt, R. E., and Schwartz, R. S. (2012). Obesity, insulin resistance, and alzheimer's disease. Obesity 20, 1549-1557. doi: 10.1038/oby.2012.19

Hofseth, L. J., Singh, U. P., Singh, N. P., Nagarkatti, M., and Nagarkatti, P. S. (2010). Taming the beast within: resveratrol suppresses colitis and prevents colon cancer. Aging 2, 183-184. doi: 10.18632/aging.100143

Hotamisligil, G. S. (2006). Inflammation and metabolic disorders. Nature 444, 860-867. doi: 10.1038/nature05485

Hou, Y., Dan, X., Babbar, M., Wei, Y., Hasselbalch, S. G., Croteau, D. L., et al. (2019). Ageing as a risk factor for neurodegenerative disease. Nat. Rev. Neurol. 15, 565-581. doi: 10.1038/s41582-019-0244-7 
Houtkooper, R. H., Pirinen, E., and Auwerx, J. (2012). Sirtuins as regulators of metabolism and healthspan. Nat. Rev. Mol. Cell Biol. 13, 225-238. doi: $10.1038 / \mathrm{nrm} 3293$

Huynh, F. K., Hershberger, K. A., and Hirschey, M. D. (2013). Targeting sirtuins for the treatment of diabetes. Diabetes Manag. 3, 245-257. doi: 10.2217/dmt.13.6

Igarashi, M., Miura, M., Williams, E., Jaksch, F., Kadowaki, T., Yamauchi, T., et al. (2019). $\mathrm{NAD}(+)$ supplementation rejuvenates aged gut adult stem cells. Aging Cell 18:e12935. doi: 10.1111/acel.12935

Ishikawa, S., and Ishikawa, F. (2020). Proteostasis failure and cellular senescence in long-term cultured postmitotic rat neurons. Aging Cell 19:e13071. doi: $10.1111 /$ acel.13071

Jayasena, T., Poljak, A., Braidy, N., Zhong, L., Rowlands, B., Muenchhoff, J., et al. (2016). Application of targeted mass spectrometry for the quantification of sirtuins in the central nervous system. Sci. Rep. 6:35391. doi: 10.1038/srep35391

Jiang, C., Li, G., Huang, P., Liu, Z., and Zhao, B. (2017). The gut microbiota and alzheimer's disease. J. Alzheimers Dis. 58, 1-15. doi: 10.3233/JAD-161141

Jiang, Y., Dong, H., Eckmann, L., Hanson, E. M., Ihn, K. C., and Mittal, R. K. (2017). Visualizing the enteric nervous system using genetically engineered double reporter mice: comparison with immunofluorescence. PLoS ONE 12:e0171239. doi: 10.1371/journal.pone.0171239

Jing, H., and Lin, H. (2015). Sirtuins in epigenetic regulation. Chem. Rev. 115, 2350-2375. doi: 10.1021/cr500457h

Jung, M. J., Lee, J., Shin, N. R., Kim, M. S., Hyun, D. W., Yun, J. H., et al. (2016). Chronic repression of mTOR complex 2 induces changes in the gut microbiota of diet-induced obese mice. Sci. Rep. 6:30887. doi: 10.1038/srep30887

Kakefuda, K., Fujita, Y., Oyagi, A., Hyakkoku, K., Kojima, T., Umemura, K., et al. (2009). Sirtuin 1 overexpression mice show a reference memory deficit, but not neuroprotection. Biochem. Biophys. Res. Commun. 387, 784-788. doi: 10.1016/j.bbrc.2009.07.119

Kaluski, S., Portillo, M., Besnard, A., Stein, D., Einav, M., Zhong, L., et al. (2017). Neuroprotective functions for the histone deacetylase SIRT6. Cell Rep. 18, 3052-3062. doi: 10.1016/j.celrep.2017.03.008

Kalyani, R. R., Golden, S. H., and Cefalu, W. T. (2017). Diabetes and aging: unique considerations and goals of care. Diabetes Care 40, 440-443. doi: $10.2337 /$ dci17-0005

Karuppagounder, S. S., Pinto, J. T., Xu, H., Chen, H. L., Beal, M. F., and Gibson, G. E. (2009). Dietary supplementation with resveratrol reduces plaque pathology in a transgenic model of alzheimer's disease. Neurochem. Int. 54, 111-118. doi: 10.1016/j.neuint.2008.10.008

Kim, D., Nguyen, M. D., Dobbin, M. M., Fischer, A., Sananbenesi, F., Rodgers, J. T., et al. (2007). SIRT1 deacetylase protects against neurodegeneration in models for alzheimer's disease and amyotrophic lateral sclerosis. EMBO J. 26, 3169-3179. doi: 10.1038/sj.emboj.7601758

Kim, H. K., Youn, B. S., Shin, M. S., Namkoong, C., Park, K. H., Baik, J. H., et al. (2010). Hypothalamic Angptl4/Fiaf is a novel regulator of food intake and body weight. Diabetes 59, 2772-2780. doi: 10.2337/db10-0145

Kim, M., de la Pena, J. B., Cheong, J. H., and Kim, H. J. (2018). Neurobiological functions of the period circadian clock 2 gene, per2. Biomol. Ther. 26, 358-367. doi: 10.4062/biomolther.2017.131

Kim, S. H., Lu, H. F., and Alano, C. C. (2011). Neuronal Sirt3 protects against excitotoxic injury in mouse cortical neuron culture. PLOS ONE 6:e14731. doi: 10.1371/journal.pone.0014731

Koh, A., De Vadder, F., Kovatcheva-Datchary, P., and Backhed, F. (2016). From dietary fiber to host physiology: short-chain fatty acids as key bacterial metabolites. Cell 165, 1332-1345. doi: 10.1016/j.cell.2016.05.041

Komaroff, A. L. (2017). The microbiome and risk for obesity and diabetes. JAMA 317, 355-356. doi: 10.1001/jama.2016.20099

Kugel, S., and Mostoslavsky, R. (2014). Chromatin and beyond: the multitasking roles for SIRT6. Trends Biochem. Sci. 39, 72-81. doi: 10.1016/j.tibs.2013.12.002

Lakhan, S. E., and Kirchgessner, A. (2010). Neuroinflammation in inflammatory bowel disease. J. Neuroinflammation 7, 37-37. doi: 10.1186/1742-2094-7-37

Lakhan, S. E., and Kirchgessner, A. (2011). Gut microbiota and sirtuins in obesity-related inflammation and bowel dysfunction. J. Transl. Med. 9:202. doi: 10.1186/1479-5876-9-202

Lan, F., Weikel, K. A., Cacicedo, J. M., and Ido, Y. (2017). Resveratrol-induced AMP-activated protein kinase activation is cell-type dependent: lessons from basic research for clinical application. Nutrients 9:751. doi: 10.3390/nu9070751
Larrosa, M., Yanez-Gascon, M. J., Selma, M. V., Gonzalez-Sarrias, A., Toti, S., Ceron, J. J., et al. (2009). Effect of a low dose of dietary resveratrol on colon microbiota, inflammation and tissue damage in a DSS-induced colitis rat model. J. Agric. Food Chem. 57, 2211-2220. doi: 10.1021/jf803638d

Lazo-Gomez, R., and Tapia, R. (2017). Quercetin prevents spinal motor neuron degeneration induced by chronic excitotoxic stimulus by a sirtuin 1dependent mechanism. Transl. Neurodegener. 6:31. doi: 10.1186/s40035-0170102-8

Lee, J., Kim, Y., Liu, T., Hwang, Y. J., Hyeon, S. J., Im, H., et al. (2018). SIRT3 deregulation is linked to mitochondrial dysfunction in alzheimer's disease. Aging Cell 17:e12679. doi: 10.1111/acel.12679

Lee, S. H., Lee, J. H., Lee, H. Y., and Min, K. J. (2019). Sirtuin signaling in cellular senescence and aging. BMB Rep. 52, 24-34. doi: 10.5483/BMBRep.2019.52.1.290

Li, J., Ma, W., and Wang, S. (2011). Slower gastric emptying in high-fat diet induced obese rats is associated with attenuated plasma ghrelin and elevated plasma leptin and cholecystokinin concentrations. Regul. Pept. 171, 53-57. doi: 10.1016/j.regpep.2011.07.004

Ling, K. H., Wan, M. L., El-Nezami, H., and Wang, M. (2016). Protective capacity of resveratrol, a natural polyphenolic compound, against deoxynivalenolinduced intestinal barrier dysfunction and bacterial translocation. Chem. Res. Toxicol. 29, 823-833. doi: 10.1021/acs.chemrestox.6b00001

Liu, L., Peritore, C., Ginsberg, J., Kayhan, M., and Donmez, G. (2015a). SIRT3 attenuates MPTP-induced nigrostriatal degeneration via enhancing mitochondrial antioxidant capacity. Neurochem. Res. 40, 600-608. doi: 10.1007/s11064-014-1507-8

Liu, L., Peritore, C., Ginsberg, J., Shih, J., Arun, S., and Donmez, G. (2015b). Protective role of SIRT5 against motor deficit and dopaminergic degeneration in MPTP-induced mice model of parkinson's disease. Behav. Brain Res. 281, 215-221. doi: 10.1016/j.bbr.2014.12.035

Liu, R. S., Lemieux, L., Bell, G. S., Sisodiya, S. M., Shorvon, S. D., Sander, J. W., et al. (2003). A longitudinal study of brain morphometrics using quantitative magnetic resonance imaging and difference image analysis. Neuroimage 20, 22-33. doi: 10.1016/S1053-8119(03)00219-2

Liu, R. T. (2017). The microbiome as a novel paradigm in studying stress and mental health. Am. Psychol. 72, 655-667. doi: 10.1037/amp0000058

Lo Sasso, G., Ryu, D., Mouchiroud, L., Fernando, S. C., Anderson, C. L., Katsyuba, E., et al. (2014). Loss of Sirtl function improves intestinal anti-bacterial defense and protects from colitis-induced colorectal cancer. PLOS ONE 9:e102495. doi: 10.1371/journal.pone.0102495

Maragakis, N. J., and Rothstein, J. D. (2006). Mechanisms of disease: astrocytes in neurodegenerative disease. Nat. Clin. Pract. Neurol. 2, 679-689. doi: 10.1038/ncpneuro0355

Martinez-Redondo, P., and Vaquero, A. (2013). The diversity of histone versus nonhistone sirtuin substrates. Genes Cancer 4, 148-163. doi: $10.1177 / 1947601913483767$

Mawe, G. M., Strong, D. S., and Sharkey, K. A. (2009). Plasticity of enteric nerve functions in the inflamed and postinflamed gut. Neurogastroenterol. Motil. 21, 481-491. doi: 10.1111/j.1365-2982.2009.01291.x

Mazzoli, R., and Pessione, E. (2016). The neuro-endocrinological role of microbial glutamate and GABA signaling. Front. Microbiol. 7:1934. doi: $10.3389 /$ fmicb.2016.01934

McGregor, G., and Harvey, J. (2018). Regulation of hippocampal synaptic function by the metabolic hormone, leptin: implications for health and neurodegenerative disease. Front. Cell. Neurosci. 12:340. doi: $10.3389 /$ fncel.2018.00340

McMenamin, C. A., Clyburn, C., and Browning, K. N. (2018). High-fat diet during the perinatal period induces loss of myenteric nitrergic neurons and increases enteric glial density, prior to the development of obesity. Neuroscience 393, 369-380. doi: 10.1016/j.neuroscience.2018.09.033

Min, S. W., Cho, S. H., Zhou, Y., Schroeder, S., Haroutunian, V., Seeley, W. W., et al. (2010). Acetylation of tau inhibits its degradation and contributes to tauopathy. Neuron 67, 953-966. doi: 10.1016/j.neuron.2010.08.044

Mudo, G., Makela, J., Di Liberto, V., Tselykh, T. V., Olivieri, M., Piepponen, P., et al. (2012). Transgenic expression and activation of PGC-1alpha protect dopaminergic neurons in the MPTP mouse model of parkinson's disease. Cell. Mol. Life Sci. 69, 1153-1165. doi: 10.1007/s00018-011-0850-z 
Nagy, N., and Goldstein, A. M. (2017). Enteric nervous system development: a crest cell's journey from neural tube to colon. Semin. Cell Dev. Biol. 66, 94-106. doi: 10.1016/j.semcdb.2017.01.006

Nezami, B. G., and Srinivasan, S. (2010). Enteric nervous system in the small intestine: pathophysiology and clinical implications. Curr. Gastroenterol. Rep. 12, 358-365. doi: 10.1007/s11894-010-0129-9

Nicholson, J. K., Holmes, E., Kinross, J., Burcelin, R., Gibson, G., Jia, W., et al. (2012). Host-gut microbiota metabolic interactions. Science 336, 1262-1267. doi: $10.1126 /$ science. 1223813

Nieto-Estevez, V., Defterali, C., and Vicario-Abejon, C. (2016). IGF-I: a key growth factor that regulates neurogenesis and synaptogenesis from embryonic to adult stages of the brain. Front. Neurosci. 10:52. doi: 10.3389/fnins.2016.00052

North, B. J., and Verdin, E. (2007). Interphase nucleo-cytoplasmic shuttling and localization of SIRT2 during mitosis. PLOS ONE 2:e784. doi: 10.1371/journal.pone.0000784

Oberdoerffer, P., Michan, S., McVay, M., Mostoslavsky, R., Vann, J., Park, S. K., et al. (2008). SIRT1 redistribution on chromatin promotes genomic stability but alters gene expression during aging. Cell 135, 907-918. doi: $10.1016 /$ j.cell.2008.10.025

O’Brien, P. D., Hinder, L. M., Callaghan, B. C., and Feldman, E. L. (2017). Neurological consequences of obesity. Lancet Neurol. 16, 465-477. doi: 10.1016/S1474-4422(17)30084-4

O’Mahony, S. M., Clarke, G., Borre, Y. E., Dinan, T. G., and Cryan, J. F. (2015). Serotonin, tryptophan metabolism and the brain-gut-microbiome axis. Behav. Brain Res. 277, 32-48. doi: 10.1016/j.bbr.2014.07.027

Outeiro, T. F., Kontopoulos, E., Altmann, S. M., Kufareva, I., Strathearn, K. E., Amore, A. M., et al. (2007). Sirtuin 2 inhibitors rescue alpha-synucleinmediated toxicity in models of parkinson's disease. Science 317, 516-519. doi: $10.1126 /$ science. 1143780

Paulo, L., Ferreira, S., Gallardo, E., Queiroz, J. A., and Domingues, F. (2010). Antimicrobial activity and effects of resveratrol on human pathogenic bacteria. World J. Microbiol. Biotechnol. 26, 1533-1538. doi: 10.1007/s11274-010-0325-7

Phillips, R. J., Kieffer, E. J., and Powley, T. L. (2003). Aging of the myenteric plexus: neuronal loss is specific to cholinergic neurons. Auton. Neurosci. 106, 69-83. doi: 10.1016/S1566-0702(03)00072-9

Pistollato, F., Sumalla Cano, S., Elio, I., Masias Vergara, M., Giampieri, F., and Battino, M. (2016). Role of gut microbiota and nutrients in amyloid formation and pathogenesis of alzheimer disease. Nutr. Rev. 74, 624-634. doi: 10.1093/nutrit/nuw023

Poirier, A. A., Aube, B., Cote, M., Morin, N., Di Paolo, T., and Soulet, D. (2016). Gastrointestinal dysfunctions in parkinson's disease: symptoms and treatments. Parkinsons Dis. 2016:6762528. doi: 10.1155/2016/6762528

Popa-Wagner, A., Dumitrascu, D. I., Capitanescu, B., Petcu, E. B., Surugiu, R., Fang, W. H., et al. (2020). Dietary habits, lifestyle factors and neurodegenerative diseases. Neural Regen Res. 15, 394-400. doi: 10.4103/1673-5374.266045

Porter, A. J., Wattchow, D. A., Brookes, S. J., and Costa, M. (2002). Cholinergic and nitrergic interneurones in the myenteric plexus of the human colon. Gut 51, 70-75. doi: 10.1136/gut.51.1.70

Przedborski, S., Vila, M., and Jackson-Lewis, V. (2003). Neurodegeneration: what is it and where are we? J. Clin. Invest. 111, 3-10. doi: 10.1172/JCI200317522

Puig, K. L., Lutz, B. M., Urquhart, S. A., Rebel, A. A., Zhou, X., Manocha, G. D., et al. (2015). Overexpression of mutant amyloid-beta protein precursor and presenilin 1 modulates enteric nervous system. J. Alzheimers Dis. 44, 1263-1278. doi: 10.3233/JAD-142259

Qiao, Y., Sun, J., Xia, S., Tang, X., Shi, Y., and Le, G. (2014). Effects of resveratrol on gut microbiota and fat storage in a mouse model with high-fat-induced obesity. Food Funct. 5, 1241-1249. doi: 10.1039/c3fo60630a

Qin, W., Yang, T., Ho, L., Zhao, Z., Wang, J., Chen, L., et al. (2006). Neuronal SIRT1 activation as a novel mechanism underlying the prevention of alzheimer disease amyloid neuropathology by calorie restriction. J. Biol. Chem. 281, 21745-21754. doi: 10.1074/jbc.M602909200

Qiu, C., Kivipelto, M., and von Strauss, E. (2009). Epidemiology of alzheimer's disease: occurrence, determinants, and strategies toward intervention. Dialogues Clin. Neurosci. 11, 111-128. doi: 10.31887/DCNS.2009.11.2/cqiu

Quigley, E. M. M. (2017). Microbiota-brain-gut axis and neurodegenerative diseases. Curr. Neurol. Neurosci. Rep. 17:94. doi: 10.1007/s11910-0170802-6
Raimundo, A. F., Ferreira, S., Martins, I. C., and Menezes, R. (2020). Islet amyloid polypeptide: a partner in crime with abeta in the pathology of alzheimer's disease. Front. Mol. Neurosci. 13:35. doi: 10.3389/fnmol.2020.00035

Ramadori, G., Lee, C. E., Bookout, A. L., Lee, S., Williams, K. W., Anderson, J., et al. (2008). Brain SIRT1: anatomical distribution and regulation by energy availability. J. Neurosci. 28, 9989-9996. doi: 10.1523/JNEUROSCI.3257-08.2008

Ramanoel, S., Hoyau, E., Kauffmann, L., Renard, F., Pichat, C., Boudiaf, N., et al. (2018). Gray matter volume and cognitive performance during normal aging. A voxel-based morphometry study. Front. Aging Neurosci. 10:235. doi: 10.3389/fnagi.2018.00235

Ramesh, S., Govindarajulu, M., Lynd, T., Briggs, G., Adamek, D., Jones, E., et al. (2018). SIRT3 activator honokiol attenuates beta-amyloid by modulating amyloidogenic pathway. PLoS ONE 13:e0190350. doi: 10.1371/journal.pone.0190350

Ramos-Lobo, A. M., and Donato, J. Jr. (2017). The role of leptin in health and disease. Temperature 4, 258-291. doi: 10.1080/23328940.2017.1327003

Rao, M., and Gershon, M. D. (2016). The bowel and beyond: the enteric nervous system in neurological disorders. Nat. Rev. Gastroenterol. Hepatol. 13, 517-528. doi: 10.1038/nrgastro.2016.107

Richards, P., Parker, H. E., Adriaenssens, A. E., Hodgson, J. M., Cork, S. C., Trapp, S., et al. (2014). Identification and characterization of GLP-1 receptorexpressing cells using a new transgenic mouse model. Diabetes 63, 1224-1233. doi: $10.2337 / \mathrm{db} 13-1440$

Saffrey, M. J. (2013). Cellular changes in the enteric nervous system during ageing. Dev. Biol. 382, 344-355. doi: 10.1016/j.ydbio.2013.03.015

Sampson, T. R., Debelius, J. W., Thron, T., Janssen, S., Shastri, G. G., Ilhan, Z. E., et al. (2016). Gut microbiota regulate motor deficits and neuroinflammation in a model of Parkinson's disease. Cell 167, 1469-1480.e1412. doi: 10.1016/j.cell.2016.11.018

Sansone, L., Reali, V., Pellegrini, L., Villanova, L., Aventaggiato, M., Marfe, G., et al. (2013). SIRT1 silencing confers neuroprotection through IGF-1 pathway activation. J. Cell. Physiol. 228, 1754-1761. doi: 10.1002/jcp.24334

Santer, R. M., and Baker, D. M. (1988). Enteric neuron numbers and sizes in auerbach's plexus in the small and large intestine of adult and aged rats. J. Auton. Nerv. Syst. 25, 59-67. doi: 10.1016/0165-1838(88)90008-2

Semar, S., Klotz, M., Letiembre, M., Van Ginneken, C., Braun, A., Jost, V., et al. (2013). Changes of the enteric nervous system in amyloid-beta protein precursor transgenic mice correlate with disease progression. J. Alzheimers Dis. 36, 7-20. doi: 10.3233/JAD-120511

Sharma, N., and Nehru, B. (2015). Characterization of the lipopolysaccharide induced model of parkinson's disease: role of oxidative stress and neuroinflammation. Neurochem. Int. 87, 92-105. doi: 10.1016/j.neuint.2015.06.004

Sharma, S., and Tripathi, P. (2019). Gut microbiome and type 2 diabetes: where we are and where to go? J. Nutr. Biochem. 63, 101-108. doi: 10.1016/j.jnutbio.2018.10.003

Shi, H., Deng, H. X., Gius, D., Schumacker, P. T., Surmeier, D. J., and Ma, Y. C. (2017). Sirt3 protects dopaminergic neurons from mitochondrial oxidative stress. Hum. Mol. Genet. 26, 1915-1926. doi: 10.1093/hmg/ddx100

Shi, Z., Li, C., Yin, Y., Yang, Z., Xue, H., Mu, N., et al. (2018). Aerobic interval training regulated sirt3 attenuates high-fat-diet-associated cognitive dysfunction. Biomed Res. Int. 2018:2708491. doi: 10.1155/2018/2708491

Sidorova-Darmos, E., Wither, R. G., Shulyakova, N., Fisher, C., Ratnam, M., Aarts, M., et al. (2014). Differential expression of sirtuin family members in the developing, adult, and aged rat brain. Front. Aging Neurosci. 6:333. doi: $10.3389 /$ fnagi.2014.00333

Silva, D. F., Esteves, A. R., Oliveira, C. R., and Cardoso, S. M. (2017). Mitochondrial metabolism power SIRT2-dependent deficient traffic causing Alzheimer's-disease related pathology. Mol. Neurobiol. 54, 4021-4040. doi: 10.1007/s12035-016-9951-x

Singh, P., Hanson, P. S., and Morris, C. M. (2017). SIRT1 ameliorates oxidative stress induced neural cell death and is down-regulated in parkinson's disease. BMC Neurosci. 18:46. doi: 10.1186/s12868-017-0364-1

Snoek, S. A., Verstege, M. I., Boeckxstaens, G. E., van den Wijngaard, R. M., and de Jonge, W. J. (2010). The enteric nervous system as a regulator of intestinal epithelial barrier function in health and disease. Expert Rev. Gastroenterol. Hepatol. 4, 637-651. doi: 10.1586/egh.10.51 
Squier, T. C. (2001). Oxidative stress and protein aggregation during biological aging. Exp. Gerontol. 36, 1539-1550. doi: 10.1016/S0531-5565(01)00139-5

Stenkamp-Strahm, C. M., Nyavor, Y. E., Kappmeyer, A. J., Horton, S., Gericke, M., and Balemba, O. B. (2015). Prolonged high fat diet ingestion, obesity, and type 2 diabetes symptoms correlate with phenotypic plasticity in myenteric neurons and nerve damage in the mouse duodenum. Cell Tissue Res. 361, 411-426. doi: 10.1007/s00441-015-2132-9

Stern, J. H., Rutkowski, J. M., and Scherer, P. E. (2016). Adiponectin, leptin, and fatty acids in the maintenance of metabolic homeostasis through adipose tissue crosstalk. Cell Metab. 23, 770-784. doi: 10.1016/j.cmet.2016.04.011

Stillman, C. M., Weinstein, A. M., Marsland, A. L., Gianaros, P. J., and Erickson, K. I. (2017). Body-brain connections: the effects of obesity and behavioral interventions on neurocognitive aging. Front. Aging Neurosci. 9:115. doi: $10.3389 /$ fnagi.2017.00115

Sudo, N. (2019). Biogenic amines: signals between commensal microbiota and gut physiology. Front. Endocrinol. 10:504. doi: 10.3389/fendo.2019.00504

Sun, T., Li, D., Hu, S., Huang, L., Sun, H., Yang, S., et al. (2018). Aging-dependent decrease in the numbers of enteric neurons, interstitial cells of cajal and expression of connexin 43 in various regions of gastrointestinal tract. Aging 10, 3851-3865. doi: 10.18632/aging.101677

Sung, M. M., Kim, T. T., Denou, E., Soltys, C. M., Hamza, S. M., Byrne, N. J., et al. (2017). Improved glucose homeostasis in obese mice treated with resveratrol is associated with alterations in the gut microbiome. Diabetes 66, 418-425. doi: $10.2337 / \mathrm{db} 16-0680$

Tazoe, H., Otomo, Y., Kaji, I., Tanaka, R., Karaki, S. I., and Kuwahara, A. (2008). Roles of short-chain fatty acids receptors, GPR41 and GPR43 on colonic functions. J. Physiol. Pharmacol. 59(Suppl. 2), 251-262.

Terribilli, D., Schaufelberger, M. S., Duran, F. L., Zanetti, M. V., Curiati, P. K., Menezes, P. R., et al. (2011). Age-related gray matter volume changes in the brain during non-elderly adulthood. Neurobiol. Aging 32, 354-368. doi: 10.1016/j.neurobiolaging.2009.02.008

Thomas, K., Beyer, F., Lewe, G., Zhang, R., Schindler, S., Schonknecht, P., et al. (2019). Higher body mass index is linked to altered hypothalamic microstructure. Sci. Rep. 9:17373. doi: 10.1038/s41598-019-53578-4

Thorpe, R. J. Jr., and Ferraro, K. F. (2004). Aging, obesity, and mortality: misplaced concern about obese older people? Res. Aging 26, 108-129. doi: $10.1177 / 0164027503258738$

Timper, K., and Bruning, J. C. (2017). Hypothalamic circuits regulating appetite and energy homeostasis: pathways to obesity. Dis. Model. Mech. 10, 679-689. doi: $10.1242 / \mathrm{dmm} .026609$

Tolhurst, G., Heffron, H., Lam, Y. S., Parker, H. E., Habib, A. M., Diakogiannaki, E., et al. (2012). Short-chain fatty acids stimulate glucagon-like peptide-1 secretion via the G-protein-coupled receptor FFAR2. Diabetes 61, 364-371. doi: $10.2337 / \mathrm{db} 11-1019$

Toorie, A. M., and Nillni, E. A. (2014). Minireview: central sirt1 regulates energy balance via the melanocortin system and alternate pathways. Mol. Endocrinol. 28, 1423-1434. doi: 10.1210/me.2014-1115

Tremaroli, V., and Backhed, F. (2012). Functional interactions between the gut microbiota and host metabolism. Nature 489, 242-249. doi: $10.1038 /$ nature 11552

Tyagi, A., Nguyen, C. U., Chong, T., Michel, C. R., Fritz, K. S., Reisdorph, N., et al. (2018). SIRT3 deficiency-induced mitochondrial dysfunction and inflammasome formation in the brain. Sci. Rep. 8:17547. doi: 10.1038/s41598-018-35890-7

Uranga, R. M., and Keller, J. N. (2019). The complex interactions between obesity, metabolism and the brain. Front. Neurosci. 13:513. doi: 10.3389/fnins.2019.00513

Uttara, B., Singh, A. V., Zamboni, P., and Mahajan, R. T. (2009). Oxidative stress and neurodegenerative diseases: a review of upstream and downstream antioxidant therapeutic options. Curr. Neuropharmacol. 7, 65-74. doi: $10.2174 / 157015909787602823$

van Olden, C., Groen, A. K., and Nieuwdorp, M. (2015). Role of intestinal microbiome in lipid and glucose metabolism in diabetes mellitus. Clin. Ther. 37, 1172-1177. doi: 10.1016/j.clinthera.2015.03.008

Vecchio, L. M., Meng, Y., Xhima, K., Lipsman, N., Hamani, C., and Aubert, I. (2018). The neuroprotective effects of exercise: maintaining a healthy brain throughout aging. Brain Plast. 4, 17-52. doi: 10.3233/BPL-180069
Verrotti, A., Prezioso, G., Scattoni, R., and Chiarelli, F. (2014). Autonomic neuropathy in diabetes mellitus. Front. Endocrinol. 5:205. doi: 10.3389 /fendo.2014.00205

Villalba, J. M., and Alcain, F. J. (2012). Sirtuin activators and inhibitors. Biofactors 38, 349-359. doi: 10.1002/biof.1032

Vingtdeux, V., Giliberto, L., Zhao, H., Chandakkar, P., Wu, Q., Simon, J. E., et al. (2010). AMP-activated protein kinase signaling activation by resveratrol modulates amyloid-beta peptide metabolism. J. Biol. Chem. 285, 9100-9113. doi: 10.1074/jbc.M109.060061

Voukali, E., Shotton, H. R., and Lincoln, J. (2011). Selective responses of myenteric neurons to oxidative stress and diabetic stimuli. Neurogastroenterol. Motil. 23, 964-e411. doi: 10.1111/j.1365-2982.2011.01778.x

Wade, P. R., and Cowen, T. (2004). Neurodegeneration: a key factor in the ageing gut. Neurogastroenterol. Motil. 16(Suppl. 1), 19-23. doi: $10.1111 / j .1743-3150.2004 .00469 . x$

Walsh, K. T., and Zemper, A. E. (2019). The enteric nervous system for epithelial researchers: basic anatomy, techniques, and interactions with the epithelium. Cell Mol. Gastroenterol. Hepatol. 8, 369-378. doi: 10.1016/j.jcmgh.2019. 05.003

Wang, N., Han, Q., Wang, G., Ma, W. P., Wang, J., Wu, W. X., et al. (2016). Resveratrol protects oxidative stress-induced intestinal epithelial barrier dysfunction by upregulating heme oxygenase-1 expression. Dig. Dis. Sci. 61, 2522-2534. doi: 10.1007/s10620-016-4184-4

Wang, P., Gao, J., Ke, W., Wang, J., Li, D., Liu, R., et al. (2020). Resveratrol reduces obesity in high-fat diet-fed mice via modulating the composition and metabolic function of the gut microbiota. Free Radic. Biol. Med. 156, 83-98. doi: 10.1016/j.freeradbiomed.2020.04.013

Wang, Y., Shi, X., Qi, J., Li, X., Uray, K., and Guan, X. (2012). SIRT1 inhibits the mouse intestinal motility and epithelial proliferation. Am. J. Physiol. Gastrointest. Liver Physiol. 302, G207-217. doi: 10.1152/ajpgi.003 02.2011

Wellman, A. S., Metukuri, M. R., Kazgan, N., Xu, X., Xu, Q., Ren, N. S. X., et al. (2017). Intestinal epithelial sirtuin 1 regulates intestinal inflammation during aging in mice by altering the intestinal microbiota. Gastroenterology 153 , 772-786. doi: 10.1053 /j.gastro.2017.05.022

Wilson, R. S., Leurgans, S. E., Boyle, P. A., Schneider, J. A., and Bennett, D. A. (2010). Neurodegenerative basis of age-related cognitive decline. Neurology 75 , 1070-1078. doi: 10.1212/WNL.0b013e3181f39adc

Wu, D., Li, Y., Zhu, K. S., Wang, H., and Zhu, W. G. (2018). Advances in cellular characterization of the sirtuin isoform, SIRT7. Front. Endocrinol. 9:652. doi: $10.3389 /$ fendo.2018.00652

Wyss-Coray, T. (2016). Ageing, neurodegeneration and brain rejuvenation. Nature 539, 180-186. doi: 10.1038/nature20411

Xiong, Y., Miyamoto, N., Shibata, K., Valasek, M. A., Motoike, T., Kedzierski, R. M., et al. (2004). Short-chain fatty acids stimulate leptin production in adipocytes through the G protein-coupled receptor GPR41. Proc. Natl. Acad. Sci. U.S.A. 101, 1045-1050. doi: 10.1073/pnas.2637002100

Yamamoto, H., Schoonjans, K., and Auwerx, J. (2007). Sirtuin functions in health and disease. Mol. Endocrinol. 21, 1745-1755. doi: 10.1210/me.20 07-0079

Yan, W. W., Liang, Y. L., Zhang, Q. X., Wang, D., Lei, M. Z., Qu, J., et al. (2018). Arginine methylation of SIRT7 couples glucose sensing with mitochondria biogenesis. EMBO Rep. 19:e46377. doi: 10.15252/embr.201846377

Yannielli, P. C., Molyneux, P. C., Harrington, M. E., and Golombek, D. A. (2007). Ghrelin effects on the circadian system of mice. J. Neurosci. 27, 2890-2895. doi: 10.1523/JNEUROSCI.3913-06.2007

Yarandi, S. S., and Srinivasan, S. (2014). Diabetic gastrointestinal motility disorders and the role of enteric nervous system: current status and future directions. Neurogastroenterol. Motil. 26, 611-624. doi: 10.1111/nmo.12330

Ye, L., Li, G., Goebel, A., Raju, A. V., Kong, F., Lv, Y., et al. (2020). Caspase-11mediated enteric neuronal pyroptosis underlies western diet-induced colonic dysmotility. J. Clin. Invest. 130, 3621-3636. doi: 10.1172/JCI130176

Zeisel, A., Hochgerner, H., Lonnerberg, P., Johnsson, A., Memic, F., van der Zwan, J., et al. (2018). Molecular architecture of the mouse nervous system. Cell 174, 999-1014.e1022. doi: 10.1016/j.cell.2018.06.021

Zheng, J., Shi, L., Liang, F., Xu, W., Li, T., Gao, L., et al. (2018). Sirt3 ameliorates oxidative stress and mitochondrial dysfunction after intracerebral 
hemorrhage in diabetic rats. Front. Neurosci. 12:414. doi: 10.3389/fnins.2018. 00414

Zhong, L., D’Urso, A., Toiber, D., Sebastian, C., Henry, R. E., Vadysirisack, D. D., et al. (2010). The histone deacetylase sirt6 regulates glucose homeostasis via Hif1alpha. Cell 140, 280-293. doi: 10.1016/j.cell.2009.12.041

Zhong, L., and Mostoslavsky, R. (2010). SIRT6: a master epigenetic gatekeeper of glucose metabolism. Transcription 1, 17-21. doi: 10.4161/trns.1. 1.12143

Zuo, T., and Ng, S. C. (2018). The gut microbiota in the pathogenesis and therapeutics of inflammatory bowel disease. Front. Microbiol. 9:2247. doi: $10.3389 /$ fmicb.2018.02247
Conflict of Interest: The authors declare that the research was conducted in the absence of any commercial or financial relationships that could be construed as a potential conflict of interest.

Copyright (C) 2020 Chandramowlishwaran, Vijay, Abraham, Li, Mwangi and Srinivasan. This is an open-access article distributed under the terms of the Creative Commons Attribution License (CC BY). The use, distribution or reproduction in other forums is permitted, provided the original author(s) and the copyright owner(s) are credited and that the original publication in this journal is cited, in accordance with accepted academic practice. No use, distribution or reproduction is permitted which does not comply with these terms. 